\title{
MYC inhibitors in multiple myeloma
}

\author{
Sandra Martínez-Martín ${ }^{1,2,3}$, Laura Soucek ${ }^{1,2,3,4}$ \\ 'Preclinical \& Translational Research Program, Vall d'Hebron Institute of Oncology (VHIO), Vall d'Hebron Barcelona Hospital \\ Campus, Barcelona 08035, Spain. \\ ${ }^{2}$ Peptomyc S.L., Vall d'Hebron Barcelona Hospital Campus, Barcelona 08035, Spain. \\ ${ }^{3}$ Department of Biochemistry and Molecular Biology, Universitat Autònoma de Barcelona, Bellaterra 08193, Spain. \\ ${ }^{4}$ Institució Catalana de Recerca i Estudis Avançats (ICREA), Barcelona 08010, Spain.
}

Correspondence to: Dr. Laura Soucek, Preclinical \& Translational Research Program, Vall d'Hebron Institute of Oncology (VHIO), Vall d'Hebron Barcelona Hospital Campus, C/ Natzaret, 115-117, Barcelona 08035, Spain. E-mail: Isoucek@vhio.net

How to cite this article: Martínez-Martín S, Soucek L. MYC inhibitors in multiple myeloma. Cancer Drug Resist 2021;4:842-65. https://dx.doi.org/10.20517/cdr.2021.55

Received: 24 Jun 2021 First Decision: 22 Jul 2021 Revised: 30 Jul 2021 Accepted: 12 Aug 2021 First online: 13 Aug 2021

Academic Editors: Godefridus J. Peters, Fatih M. Uckun Copy Editor: Xi-Jun Chen Production Editor: Xi-Jun Chen

\begin{abstract}
The importance of MYC function in cancer was discovered in the late 1970s when the sequence of the avian retrovirus that causes myelocytic leukemia was identified. Since then, over 40 years of unceasing research have highlighted the significance of this protein in malignant transformation, especially in hematologic diseases. Indeed, some of the earliest connections among the higher expression of proto-oncogenes (such as MYC), genetic rearrangements and their relation to cancer development were made in Burkitt lymphoma, chronic myeloid leukemia and mouse plasmacytomas. Multiple myeloma (MM), in particular, is a plasma cell malignancy strictly associated with MYC deregulation, suggesting that therapeutic strategies against it would be beneficial in treating this disease. However, targeting MYC was - and, somehow, still is - challenging due to its unique properties: lack of defined three-dimensional structure, nuclear localization and absence of a targetable enzymatic pocket. Despite these difficulties, however, many studies have shown the potential therapeutic impact of direct or indirect MYC inhibition. Different molecules have been tested, in fact, in the context of MM. In this review, we summarize the current status of the different compounds, including the results of their clinical testing, and propose to continue with the efforts to identify, repurpose, redesign or improve drug candidates to combine them with standard of care therapies to overcome resistance and enable better management of myeloma treatment.
\end{abstract}


Keywords: MYC inhibition, multiple myeloma, undruggable target, targeted therapies, transcription factor, epigenetics, MYC downregulation

\section{INTRODUCTION \\ Multiple myeloma}

Multiple myeloma (MM), although a rare disease, is the second most common blood cancer ${ }^{[1]}$, with over 54,000 estimated new cases in Europe ${ }^{[2]}$ and 176,000 worldwide in $2020^{[3]}$. It is a neoplasm originating from the clonal expansion of plasma cells in the bone marrow $(\mathrm{BM})^{[4]}$.

Even if recent advances in medicine have quadrupled MM patient survival in the last 40 years (from $6 \%$ to $33 \%$ for ten or more years), it remains virtually incurable, as relapse rates are as high as $90 \%{ }^{[5]}$. Indeed, the disease adopts a cyclical pattern of response to therapy and remission followed by disease progression or reappearance $e^{[6]}$, as depicted in Figure 1.

Importantly, due to the progressive aging of the population and the fact that the peak rate of MM cases is at 85-89 years ${ }^{[7,8]}$, MM's incidence trend over time has increased by $32 \%$ since the early 1990 s and keeps growing. In fact, estimates predict that the number of incident myeloma cases will almost double by $2040^{[0]}$.

Myelomagenesis is a complex process that requires various driver genetic alterations to collude with each other, resulting in the development and progression of $\mathrm{MM}^{[10]}$. A benign and asymptomatic condition, termed monoclonal gammopathy of undetermined significance, precedes it and can evolve into another asymptomatic disorder, also classified among monoclonal gammopathies, termed smoldering multiple myeloma (SMM). All these diseases are characterized by the invasion of proliferating plasma cells in the BM and the secretion of monoclonal proteins referred to as $\mathrm{M}$ protein or $\mathrm{M}$ spike, present in large amounts in the blood and urine and used for the disease diagnosis ${ }^{[11-13]}$. This protein is also known as paraprotein, which is essentially a single antibody excessively produced by abnormal plasma cells.

MM is a highly heterogeneous cancer marked by clonal diversity ${ }^{[14]}$. It starts with underlying germline events, followed by primary - frequently initiating - and secondary genomic aberrations that lead to tumor progression. Using integrated genomics on newly diagnosed patients with $\mathrm{MM}$, Walker et al. ${ }^{[15]}$, for example, identified 63 driver genes, including the most diverse oncogenes, such as FGFR3, DIS3, $P R K D 2$, $C C N D 1, I R F 4, M A F, B R A F, D I S 3, A T M, F A M 46 C$ and MYC. Among the most relevant secondary events, deregulated $M Y C$ activity is associated with disease progression ${ }^{[10]}$ and occurs in a large percentage (67\%) of $\mathrm{MM}$ case $^{[16]}$. In one of the largest genome-wide association studies to date, researchers have found several single-nucleotide polymorphisms associated with $M Y C$ activation, considered a critical exacerbating event and related to poor outcomes ${ }^{[4]}$. Secondary translocations encompassing the MYC gene are late progression events that involve an Ig enhancer in $60 \%$ of the cases (either the heavy or light chains) and seemingly no other recurrent chromosomal loci in the remaining $40 \%$ cases $^{[17]}$.

The heterogeneity of MM imposes a big challenge for its treatment with tailored therapies, which are typically directed against a unique target. Besides, as mentioned above, patients commonly relapse after receiving first-line therapy, often due to a selective pressure exerted by the treatment leading to resistant subclones outgrowth $^{[18]}$. This is the main reason researchers are currently proposing alternating the use of therapies with different mechanisms of action, which could overcome future relapses. 


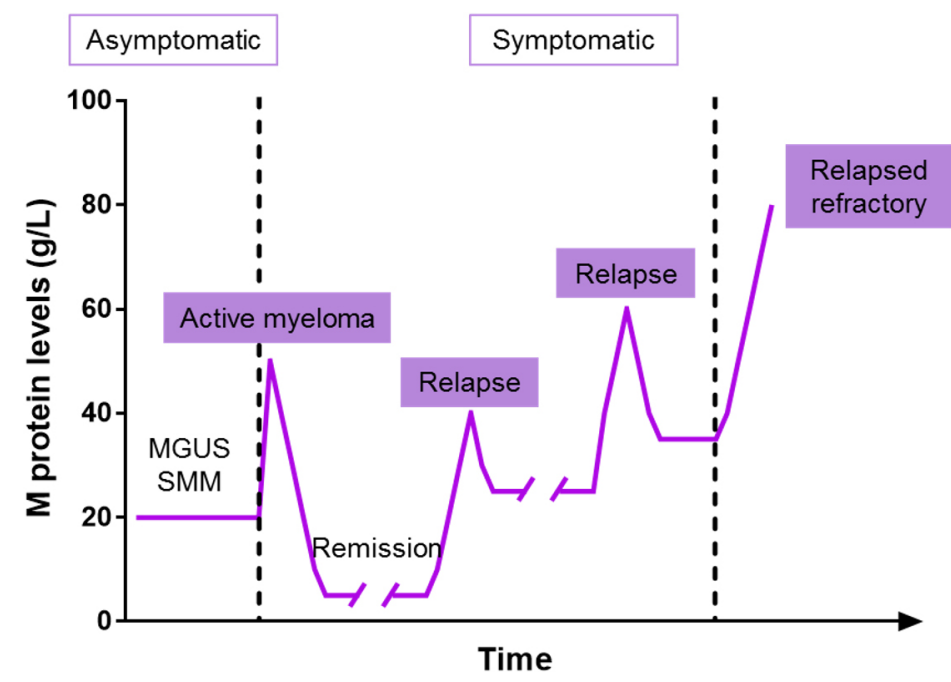

Figure 1. The response-relapse pattern in multiple myeloma patients. Monoclonal gammopathies that undergo malignant transformation are likely to respond initially to the therapy and enter in remission. However, the disease eventually relapses, and the response becomes less durable until resistance appears, resulting in relapsed refractory myeloma. Figure adapted from ${ }^{[6]}$.MGUS: Monoclonal gammopathy of undetermined significance; SMM: smoldering multiple myeloma.

Another critical aspect of MM pathophysiology is its dependence on the BM niche. Probably one of the most critical interactions in the creation of a favorable microenvironment for MM cells proliferation, survival and apoptosis resistance is their relationship with BM stromal cells (BMSCs) ${ }^{[4]}$. The cell-cell crosstalk through adhesion molecules such as VCAM1 and VLA-4 expressed by BMSCs and MM cells, respectively, results in the secretion of cytokines responsible for the formation of an appropriate cancerous milieu. This interaction also accounts for bone destruction, a hallmark of late-stage myeloma that significantly deteriorates the quality of life of MM patients ${ }^{[19]}$. Indeed, the development of osteolytic lesions, present in more than $80 \%$ of myeloma patients ${ }^{[20]}$, is one of the most devastating consequences of advanced $\mathrm{MM}$, caused by an imbalance between bone formation and resorption, partly due to a significant reduction in circulating osteoprotegerin ${ }^{[21]}$.

Taken together, all these pieces of evidence appeal for the research of new therapeutic options, either directed against novel targets or focused on bone disease management, to achieve fewer side effects. These new therapies could be combined or sequentially administered together with already approved drugs to render myeloma a preventable or, even better, curable disease.

\section{Personalized medicine and its limitations}

Oncology is one of the most invested fields in discovering new drug options, in an insatiable search for alternative therapies able to overcome the limitations of the already existing ones ${ }^{[22]}$. Personalized medicine, also known as precision medicine, aims to design tailored treatments against major molecular drivers of different pathologies ${ }^{[23]}$. Hence, precision oncology performs molecular profiling of tumors to identify alterations that can be translated into actionable targets ${ }^{[24]}$.

The first step in the profiling is to stratify the patients using new technologies, such as next generation sequencing or multi-omics approaches, to choose the most appropriate treatment for each individual based on their unique molecular aberrations. Very often, the most affected proteins in cancer are kinases, involved in many physiological processes of the cell $^{[23]}$. One well-characterized example is the BCR-ABL gene fusion in chronic myeloid leukemia (CML). This chromosomal defect, known as the Philadelphia chromosome, is 
the signature of CML, present in all patients suffering from this condition ${ }^{[2]}$. Its discovery led to the development of imatinib, a selective inhibitor of the constitutively active tyrosine kinase resulting from the gene fusion ${ }^{[26]}$. Thanks to imatinib, the survival rates for CML patients notably improved to $90 \%$ over 5 years and $88 \%$ over 8 years ${ }^{[25]}$. Other tyrosine kinase inhibitors then became very popular because of the broad involvement of the kinome in different malignancies. Thus, numerous small molecules against the enzymatic core or binding pockets of these proteins have been developed ever since, changing the clinical management of cancer $^{[27]}$.

Currently, over 55 targeted therapies are approved to treat different hematologic malignancies ${ }^{[28]}$. As such, they are directed against actionable molecules identified to play essential roles in the biology of immune cells or represent proteins that are highly expressed in these types of tumors. They can be categorized according to the type of target they inhibit: (1) B-cell surface markers [e.g., rituximab, an anti-CD20 monoclonal antibody ( $\mathrm{mAb}$ ), or daratumumab, an anti-CD38 $\mathrm{mAb}$; (2) survival or proliferation factor receptors (e.g., siltuximab, an anti-IL-6 $\mathrm{mAb}$ ); (3) cell signaling markers (e.g., ibrutinib, a BTK inhibitor, or idelalisib, a PI3K inhibitor); (4) cell cycle, apoptosis and proteasome machinery (e.g., bortezomib, a proteasome inhibitor, or venetoclax, a Bcl-2 inhibitor); (5) metabolism (e.g., lonidamine, a hexokinase inhibitor); and (6) microenvironment (including immune modulators, such as plerixafor, an anti-CXCR4; pembrolizumab, an anti-PD-1 antibody; CAR-T cells; or bispecific antibodies ${ }^{[29]}$.

However, as mentioned above, despite the initial success of all these different therapeutic strategies, most patients eventually relapse. Hence, the emergence of drug resistance is not only limited to conventional chemotherapy, but it extends to drugs with a targeted mode of action as well ${ }^{[30]}$. There are several mechanisms of resistance that have been primarily studied and described, including drug efflux, acquired mutations that impair drug binding, trapping in acidic vesicles, enhanced metabolism, activation of compensatory signaling pathways or remnant quiescent stem cells that are inherently resistant ${ }^{[31]}$.

$\mathrm{MM}$, in particular, is an excellent example of frequent disease recurrence through multiple compensatory mechanisms [Figure 2]. For instance, the occurrence of mutations in the proteasome machinery and the RAS/RAF signaling pathway confers resistance to proteasome inhibitors (PIs, e.g., bortezomib) and immunomodulatory agents (IMiDs, e.g., lenalidomide), respectively. Similarly, sequestrations of drugs in autophagosomes or active pumping to the outside are typical resistance mechanisms observed in MM. In addition, MM cells can get protection from the microenvironment by strengthening the interaction with supporting cells through integrins and other adhesion molecules or by increasing proliferation and survival signaling. Lastly, a reduction in the expression levels of certain proteins such as cereblon, CD38 and SLAM7 impairs the activity of targeting agents. Interestingly, CD38 and SLAM7 can also be secreted, acting as decoy receptors for mAbs (daratumumab or elotuzumab), which can be further weakened by increased expression of complement inhibitory proteins that hamper their ability to activate the complement-dependent cytotoxicity ${ }^{[32]}$.

In this scenario of multiple resistance mechanisms, liquid and on-treatment standard biopsies would clearly be beneficial for the identification of biomarkers of resistance or response, to intervene ahead of the point of no return, for instance by switching to a different drug and dosing regimen or even deciding to start combinations with other therapies ${ }^{[33]}$.

\section{MYC as a key regulator in cancer}

$M Y C$ is one of the most powerful oncogenes found to be deregulated in over half of human cancers ${ }^{[34]}$. The MYC gene encodes for a family of basic helix-loop-helix leucine zipper (bHLHZ) transcription factors 


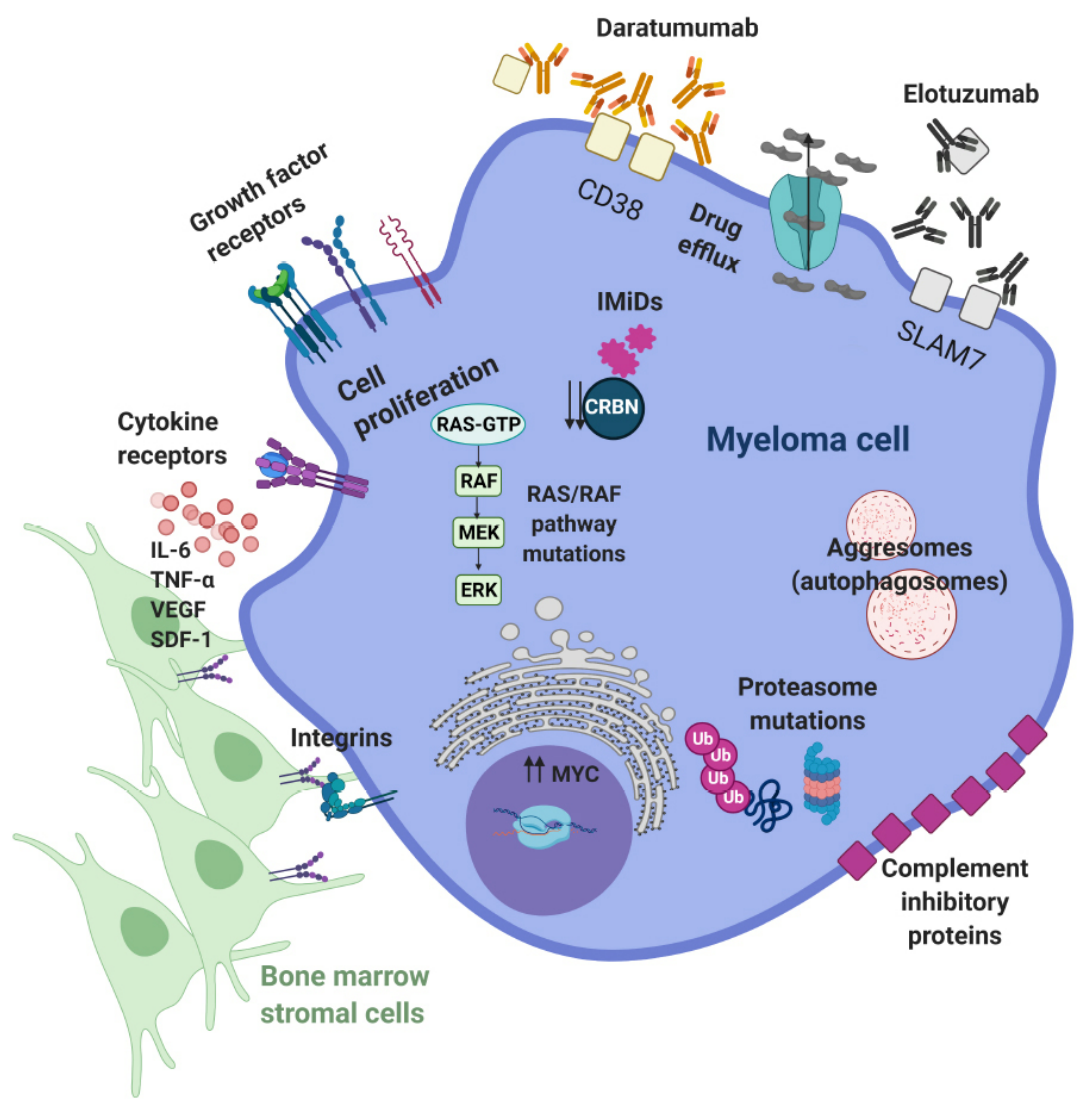

Figure 2. Examples of the most common resistance mechanisms to multiple myeloma therapies. See text for details. For a more thorough description of the resistance mechanisms, check the review from Wallington-Beddoe ${ }^{[32]}$. Figure adapted from ${ }^{[32]}$. CD38: Cluster of differentiation 38; CRBN: cereblon; ERK: extracellular signal-regulated kinases; IMiDs: immunomodulatory agents; IL-6: interleukin-6; MEK: mitogen-activated protein kinase; RAF: rapidly accelerated fibrosarcoma; SDF-1: stromal cell-derived factor; SLAM7: signaling lymphocytic activation molecule family member 7; TNF $\alpha$ : tumor necrosis factor alpha; Ub: ubiquitin; VEGF: vascular endothelial growth factor.

(TFs), comprising $c-M Y C, L-M Y C$ and $N-M Y C$, which conduct partially redundant functions depending on the tissue where they are expressed ${ }^{[35,36]}$. To mediate the many biological processes in which it is involved, MYC forms transcriptionally active dimers with its obligate partner MAX, and together they bind DNA at sequences known as E-boxes ${ }^{[37]}$.

MYC displays characteristics of an intrinsically disordered protein in its monomeric form in solution, being mostly unstructured. It comprises an $\mathrm{N}$-terminal transcriptional activation domain, followed by a canonical nuclear localization signal and a C-terminal bHLHZ domain, which is mainly unfolded until it dimerizes with $\mathrm{MAX}^{[37,38]}$.

The physiological functions of MYC include, but are not restricted to, cell proliferation and growth, apoptosis, differentiation, migration, stem cell biology, metabolism and transcriptional control over the non-coding transcriptome (miRNAs and lncRNAs ${ }^{[39-42]}$. Of note, unlike in the case of other TFs and signaling molecules, in which loss of individual proteins can often be compensated by other members of the same pathway or a parallel one, MYC function is non-redundant, as demonstrated by the lethality observed in $M Y C$ deficient mouse embryos ${ }^{[43]}$. 
Given the highly central role MYC plays in cell proliferation, its expression is tightly regulated at the transcription, mRNA and protein levels ${ }^{[37]}$. Nonetheless, many of the genetic alterations that occur in cancer uncouple MYC expression from these usual regulatory constraints: either constitutive activation of signal transduction pathways (e.g., Notch, Wnt and receptor TKs) or direct alterations of MYC, such as point mutations, leading to protein stabilization, amplifications or translocations ${ }^{[37,44]}$, can lead to its deregulation. Interestingly, however, deregulation of MYC alone is not always enough to induce tumorigenesis, so that some other genetic alterations are required. The reason is that continuous expression of MYC usually has a dual effect, inducing proliferation at first, followed by proliferative arrest, senescence or apoptosis ${ }^{[45,46]}$, so these fail-safe mechanisms need to be disabled in order for MYC to exert its full pro-tumorigenic function. Only then, aberrant expression of its target genes promotes deregulated entry and exit of the cell cycle, increased cell mass through protein biogenesis, restraint of the host immune response, relentless DNA replication, remodeling of the microenvironment, activation of the angiogenic switch, and suppression of the response to autocrine and paracrine regulatory programs and metabolic rewiring [Figure 3]. Hence, MYC activation seems to constitute the main inducer of most molecular hallmarks of cancer ${ }^{[42,45,47,48]}$.

In MM, increased MYC activity is related to disease progression ${ }^{[1,51]}$. Such deregulation can happen through many different processes - some of which are mentioned above, such as translocations or sustained activation of upstream signaling pathways, as more extensively reviewed elsewhere (Jovanović et al. ${ }^{[16]}$ ).

Many researchers worldwide have experimentally confirmed MYC's role in carcinogenesis, in many cases using conditional expression of MYC in different tissues with in vivo models, including studies on the reversibility of the process upon $M Y C$ withdrawal ${ }^{[52-55]}$. In these studies, suppression of $M Y C$ has proven to induce tumor regression not only in those tumors considered MYC-driven ${ }^{[2,56-58]}$, but also in those in which $M Y C$ is not the initiating oncogenic lesion ${ }^{[5,60]}$, suggesting that MYC inhibition would represent an effective treatment for many cancer types.

\section{MYC INHIBITION STRATEGIES}

Extensive evidence in the literature supports the idea that MYC inhibitors would have a huge impact on cancer treatment. However, no such drug is available in the clinic yet. As it happens, MYC is still considered "undruggable", a term coined for proteins believed not pharmacologically targetable ${ }^{[61]}$.

The reasons are multiple:

(1) The MYC family comprises three potentially redundant members so that complete MYC inhibition would require simultaneous blockade of all three at a time.

(2) MYC is a mainly unstructured TF, lacking a binding pocket to tamper with, and it functions mainly through protein-protein interactions (PPIs), so that targeting it with the classical small molecule therapeutic design is hardly achievable, in part due to their small interacting surface.

(3) Its localization in the nucleus supposes another challenge since the inhibitory compound would need to reach this subcellular compartment to exert its function.

(4) Finally, given the pivotal role of MYC not only in tumor biology but also in physiological conditions, it was thought that MYC inhibition could potentially cause catastrophic adverse effects in healthy tissues ${ }^{[62]}$. 


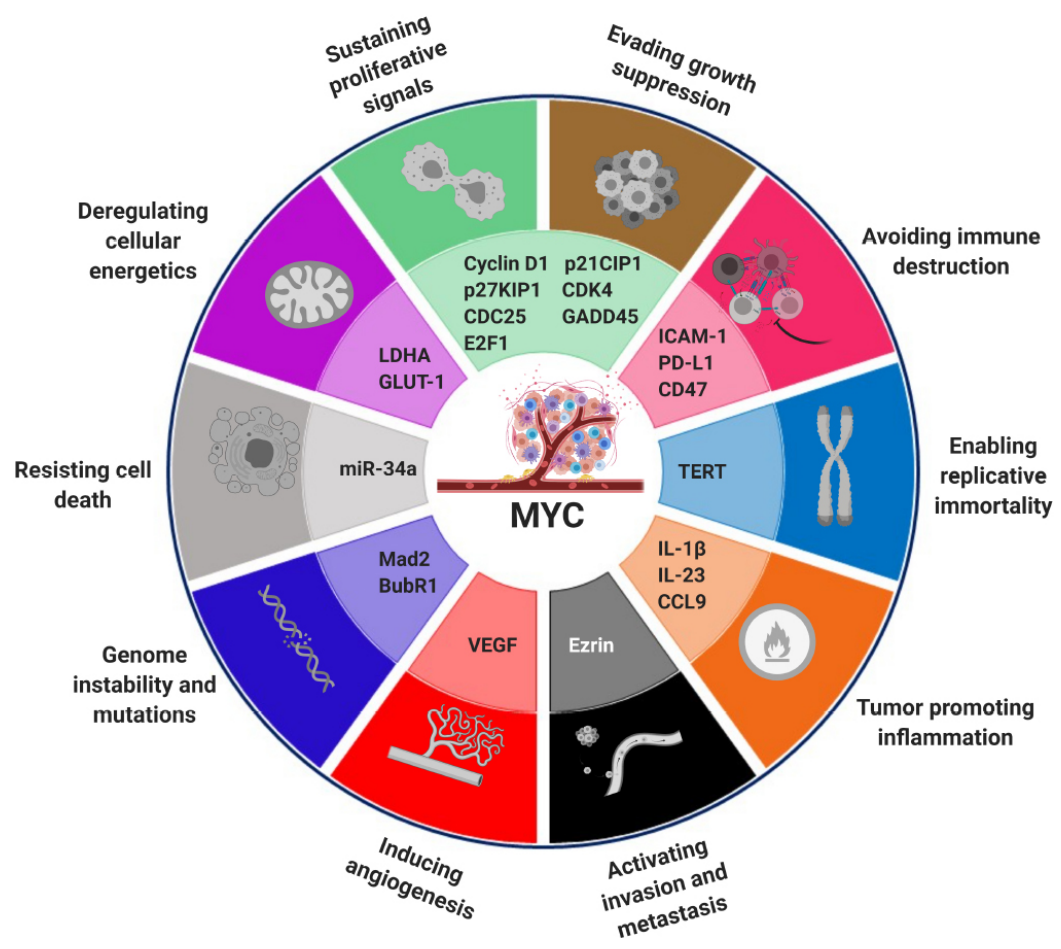

Figure 3. MYC as a central node in the hallmarks of cancer. MYC is a transcription factor and master regulator of the expression of around $30 \%$ of all human genes. As such, it instructs the differential expression of many genes, contributing to the acquisition of cancer-like properties, as defined by Hanahan and Weinberg ${ }^{[49]}$. In the image, some examples of MYC target genes involved in the tumorigenesis process are indicated next to the hallmark they impinge on. Figure adapted from ${ }^{[50]}$.

However, thanks to the design of Omomyc, a dominant-negative mutant of the bHLHZ of MYC and the best direct MYC inhibitor known to date ${ }^{[63,64]}$, we managed to prove most of these assumptions wrong. Indeed, Omomyc has been extensively characterized and validated in various cancer models, both as a transgene and as a mini-protein (for a historical perspective, refer to $^{[65]}$ ) and demonstrated the feasibility, safety and dramatic therapeutic impact of MYC inhibition.

However, Omomyc is not alone, and several investigations were or are being conducted to develop other drug candidates against this TF. The strategies used can be classified as indirect or direct MYC inhibitors, as summarized in Figure 4. In Table 1 we have synthesized the preclinical and clinical studies that encompass the specific indirect MYC inhibitors detailed in the text. In this review, we describe several inhibitors used in the context of MM, independently of their stage of development, aiming at summarizing the lesson learned from each of them.

\section{Indirect MYC inhibitors}

Because the MYC protein itself appeared to be a "slippery as an eel" target, researchers mostly opted for indirect pharmacological approaches, targeting its transcription, translation or degradation.

\section{Blockade of MYC transcription}

\section{Bromodomain and extra-terminal motif inhibitors}

Bromodomain and extra-terminal (BET) inhibitors (BETis) were found to alter the transcription of the $M Y C$ gene, which is regulated by BET proteins such as BRD4. The first compound to show this effect was JQ1, a BETi widely used in in vitro studies. JQ1 significantly downregulated MYC expression, causing a reduction in tumor burden and extending the overall survival in a MM mouse model ${ }^{[105]}$. Several second- 
Table 1. Summary of the different indirect MYC inhibitors and their development stage for hematological tumors (focused on MM)

\begin{tabular}{|c|c|c|c|c|c|}
\hline Class of inhibitor & Name & $\begin{array}{l}\text { Combined with other } \\
\text { therapies? }\end{array}$ & Mechanism of action & Clinical trials & Ref. \\
\hline \multirow[t]{5}{*}{ BET inhibitors } & OTX015 & Pls, IMiDs and chemo & $\begin{array}{l}\text { Downregulation of BRD } 4 \\
\text { Interruption of pathways and genes critical for } \\
\text { MM survival and resistance (e.g., NF-kB, c- } \\
\text { MYC) }\end{array}$ & Preclinical testing & Gu et al. ${ }^{[67]}$ \\
\hline & $\mathrm{CPI} 2 \mathrm{O3}$ & IMiDs & Downregulation of MYC, Ikaros and IRF4 & Preclinical testing & Díaz et al. ${ }^{[68]}$ \\
\hline & $\begin{array}{l}\text { AZD7543 and } \\
\text { ARV825 }\end{array}$ & $\begin{array}{l}\text { Combination of CDK9 inhibitor and } \\
\text { BET PROTAC }\end{array}$ & $\begin{array}{l}\text { Downregulation of BRD2, BRD4, MYC and } \\
\text { phosphorylated RNA polymerase II }\end{array}$ & Preclinical testing & Lim et al. ${ }^{[69]}$ \\
\hline & INCB054329 & JAK inhibitors ${ }^{\dagger}$ & $\begin{array}{l}\text { Reduced expression of IL6R and STAT3 } \\
\text { signaling. Downregulation of c-MYC, FGFR3 } \\
\text { and NSD2/MMSET/WHSC1 }\end{array}$ & Discontinued (NCT02431260) & $\begin{array}{l}{ }^{\dagger} \text { Stubbs et al. }{ }^{[70]} \\
{ }^{*} \text { Falchook et al. }{ }^{[71]}\end{array}$ \\
\hline & RO6870810 & No & $\begin{array}{l}\text { High affinity for the acetyl-lysine recognition } \\
\text { pocket of BET family (BRD4, BRD3, BRD2 and } \\
\text { BRDT) }\end{array}$ & Being evaluated (NCT03068351) & Shapiro et al. ${ }^{[72]}$ \\
\hline \multirow[t]{5}{*}{$\begin{array}{l}\text { Epigenetic } \\
\text { modulators } \\
\text { (continued) }\end{array}$} & GSK126 & No & $\begin{array}{l}\text { Increased IFN signaling and stopped IRF4-MYC } \\
\text { axis }^{\dagger}\end{array}$ & $\begin{array}{l}\text { Terminated (the maximal dose and schedule attained with } \\
\text { GSK2816126 showed insufficient evidence of clinical activity } \\
\text { and did not justify further clinical investigation) ( } \\
\text { NCT02082977) }\end{array}$ & $\begin{array}{l}\text { †Ishiguro et al. }{ }^{[73]} \\
\text { Yap et al. }{ }^{744]}\end{array}$ \\
\hline & SGC0946 & $\begin{array}{l}\text { No, but the authors suggest that } \\
\text { KO of SETD1B increases the } \\
\text { sensitivity to DOT1L inhibition }\end{array}$ & $\begin{array}{l}\text { Suppression of IRF4-MYC, ATF4, global protein } \\
\text { synthesis and alteration of ER stress pathways }\end{array}$ & Preclinical & Dafflon et al. ${ }^{[75]}$ \\
\hline & Panobinostat & Pls and IMiDs ${ }^{\ddagger}$ & Downregulation of $\mathrm{HO}-1, \mathrm{IRF} 4$ and $\mathrm{MYC}^{\dagger}$ & $\begin{array}{l}\text { Active (the results highlight the ability of resensitizing } \\
\text { patients with acquired resistance) (NCT01965353) }\end{array}$ & $\begin{array}{l}\text { Tang et al. }{ }^{[76]} \\
\text { Laubach et al. }{ }^{[77]}\end{array}$ \\
\hline & IRF4 ASO & No & Decrease of MYC and MYC targets & Recruiting (NCT04398485) & Mondala et al. ${ }^{[78]}$ \\
\hline & RRX-001 & $\begin{array}{l}\text { Bortezomib, pomalidomide, HDAC } \\
\text { inhibitor SAHA }\end{array}$ & $\begin{array}{l}\text { Causative of oxidative stress in hypoxia, } \\
\text { inhibiting global hypermethylation }\end{array}$ & Preclinical & $\begin{array}{l}\text { Das et al. }{ }^{[79]} \\
\text { Cabrales et al. }{ }^{[80]}\end{array}$ \\
\hline \multirow{4}{*}{$\begin{array}{l}\text { CDK7/CDK9 } \\
\text { inhibitors }\end{array}$} & THZ1 & Pls and $\mathrm{BH} 3$-mimetics & Downregulation of C-MYC, MCL-1 and BCL.X $X_{L}$ & Preclinical & Zhang et al. ${ }^{[81]}$ \\
\hline & $\begin{array}{l}\text { CDK9i (cpds } 66 \\
\text { and 68) }\end{array}$ & No & CDK9 inhibition in the low nanomolar range & Preclinical & Czudor et al. ${ }^{[82]}$ \\
\hline & SY-1365 & Venetoclax (BCL2 inhibitor) & $\begin{array}{l}\text { Lowering of the MCL-1 protein and alteration of } \\
\text { cell cycle and DNA repair pathways }\end{array}$ & $\begin{array}{l}\text { Solid tumors: terminated (business decision) (NCT03134638 } \\
\text { ) }\end{array}$ & Hu et al. ${ }^{[83]}$ \\
\hline & AZD4573 & Venetoclax & Depletion of MCL-1 & Recruiting (NCT03263637) & Cidado et al. ${ }^{[84]}$ \\
\hline \multirow[t]{3}{*}{$\begin{array}{l}\mathrm{mTOR} / \mathrm{PI} \mathrm{IKK} \\
\text { inhibitors }\end{array}$} & CUDC-907 & Dual HDAC and PI3K inhibitor & Decrease of MYC protein levels & $\begin{array}{l}\text { Completed (results information submitted but is not yet } \\
\text { publicly available on ClinicalTrials.gov.) (NCTO2674750) }\end{array}$ & Sun et al. ${ }^{[85]}$ \\
\hline & PIM-447 & IMiDs and Pls ${ }^{\dagger}$ & $\begin{array}{l}\text { Decreased levels of MYC and increased MAD- } \\
\text { 1. Disruption of elF4e and downregulation of } \\
\text { IRF4 }\end{array}$ & $\begin{array}{l}\text { Completed (promising single-agent activity and potential to } \\
\text { combine with other agents) (NCT01456689) }\end{array}$ & $\begin{array}{l}\text { "Paíno et al. }{ }^{[86,87]} \\
\text { "Raab et al. }{ }^{88]}\end{array}$ \\
\hline & Leflunomide & Lenalidomide ${ }^{\dagger}$ & Downregulation of MYC and inhibition of $\mathrm{TKs}^{\dagger}$ & Active (stable disease in 9/11 patients) (NCT02509052) & $\begin{array}{l}{ }^{\dagger} \text { Buettner et al. }{ }^{[89]} \\
\text { Rosenzweig et al. }{ }^{[90]}\end{array}$ \\
\hline
\end{tabular}


elFs/nuclear export Selinexor inhibitors

Inhibition of XPO1 $=$ retention of tumor suppressors and reduction of oncoproteins translation

Blockage of MYC mRNA translation MYC loss

Promoters of MYC TAZ degradation
(continued) $\quad \mathrm{NSC12}$ ABT-199 and dexamethasone Bortezomib

Mitochondrial oxidative stress and DNA damage

\section{Erdafitinib Pl and IMiDs}

AZD4547 No

7594-0037 No

Anlotinib

(AL3818)

Rapamycin + MS-275
Selective TK FGFR inhibito

Selective TK FGFR inhibito

Reduction of MYC phosphorylation on serine 62 and of its stability

Reduction of MYC phosphorylation on serine 62 and phosphorylation of threonine 58

Decreased MYC stability
Completed (objective treatment responses) (NCT02336815) ${ }^{a}$ Vogl et al. ${ }^{[91]}$ ${ }^{a}$ Chari et al. ${ }^{[92]}$ bMateos et al. ${ }^{[93]}$ ${ }^{\mathrm{B}}$ Richard et al. ${ }^{[94]}$ ${ }^{0}$ Auner et al. ${ }^{[05]}$ Grosicki et al [96] Maïga et al. ${ }^{[97]}$ Grieve et al. ${ }^{[98]}$ Ronca et al. ${ }^{[99]}$ Ronca et al. ${ }^{[99]}$

$\begin{array}{ll}\text { Completed (limited activity and low ORR) (NCT04439240) } & \text { Chae et al. }{ }^{[100]} \\ \text { Preclinical } & \text { Yao et al. }{ }^{[101]}\end{array}$

$\begin{array}{ll}\text { Completed (limited activity and low ORR) (NCT04439240) } & \text { Chae et al. }{ }^{[100} \\ \text { Preclinical } & \text { Yao et al. }{ }^{[101]}\end{array}$

Preclinica

Cao et al. ${ }^{[102]}$

$\begin{array}{ll}\text { Clinical stage for other indications } & \text { Shen et al. }{ }^{[103]} \\ \text { Preclinical } & \text { Simmons et al }{ }^{[104]}\end{array}$

'Refers to preclinical data. "Indicates clinical data. ${ }^{a}$ Refers to NCT02336815. ${ }^{b}$ Refers to NCT03110562. BET: Bromodomain and extra-terminal; Pls: proteasome inhibitors; IMiDs: immunomodulatory drugs; NF-кB: nuclear factor kappa-light-chain-enhancer of activated B cells: IRF4: interferon regulatory factor 4. CDK9: cyclin-dependent kinase 9: PROTAC: proteolysis targeting chimera: IL6R. interleukin-6 receptor: FGFR3: fibroblast growth factor receptor 3; IFN: interferon; KO: knock out; ATF4: activating transcription factor 4; ER: endoplasmic reticulum; TK: tyrosine kinase; mTORi: mTOR inhibitors; HDACi: histone deacetylase inhibitors; ASO: antisense oligonucleotides; elF: Eukaryotic translation Initiation Factor; PFS: progression free survival; ORR: overall response rate; HO-1: heme oxygenase-1; MM: multiple myeloma.

generation BETis with improved properties (e.g., superior oral or intraperitoneal bioavailability, distinct chemical structure, etc.) have been tested in preclinical models of MM either as monotherapy or combined with other agents.

OTX015 was recently demonstrated to have a considerable antitumor effect in a myeloma xenograft model that recapitulates the disseminated form of the human disease, extending the overall survival of mice ${ }^{[106]}$. The authors found that MYC levels were downregulated in two myeloma cell lines, which suggested that MYC itself could be a pharmacodynamic (PD) marker of BET inhibition, although its usefulness would be limited to hematologic tumors ${ }^{[107]}$. In a more recent study, Gu et al ${ }^{[67]}$ combined OTX015 with different antimyeloma agents (PIs, IMiDs or chemotherapy), showing that attacking the biology of myeloma cells through distinct angles could hold promise to render MM cells sensitive.

Similarly, Díaz et al. ${ }^{[68]}$ combined another BETi, CPI203, with lenalidomide and dexamethasone, two IMiDs usually used as myeloma standard therapy. This combination led to complete tumor growth arrest, accompanied by a significant reduction in MYC, IRF4 (interferon regulatory factor 4) and Ikaros positive cells by immunohistochemistry. 


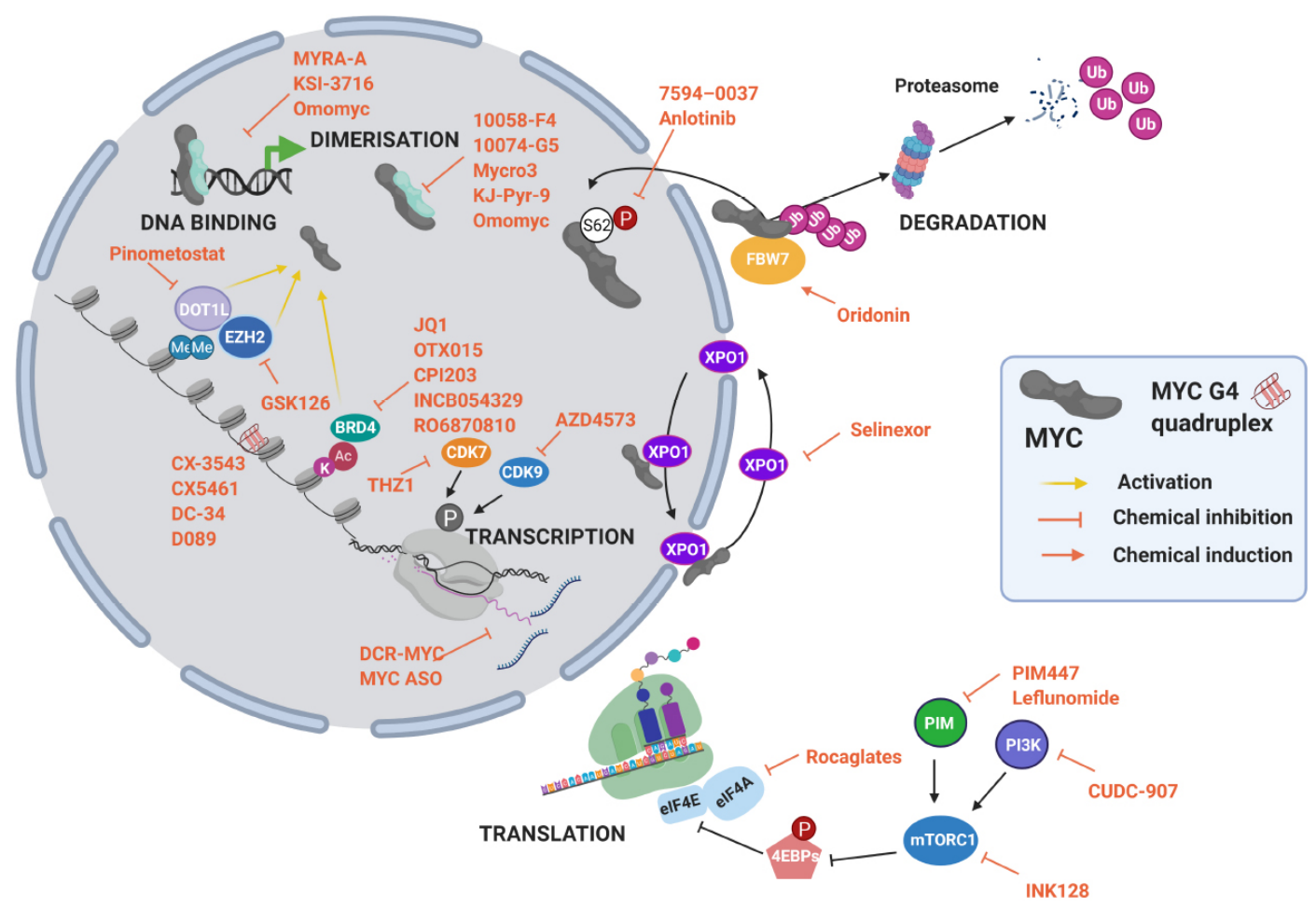

Figure 4. MYC inhibition strategies at different levels of MYC life cycle. Some examples of drugs are listed. Figure adapted from ${ }^{[66]}$.

Lim et al. ${ }^{[69]}$ were the first to combine the mechanisms of action of a CDK9 inhibitor (AZD 4573) and a BET PROTAC (ARV 825), showing synergy between them in MM. They demonstrated a blockage in proliferation and enhanced apoptosis by decreasing the phosphorylation of RNA Polymerase II, reduction of MCL-1 and MYC proteins and MYC downregulation, resulting in a very significant tumor burden reduction.

In 2019, Stubbs et al. ${ }^{[70]}$ tested INCB054329 in various myeloma cells, alone or combined with JAK inhibitors, showing better efficacy than either compound alone in in vivo models, suggesting that the intelligent design of novel combination approaches could overcome the tumor heterogeneity and complexity. Interestingly, Falchook et al. ${ }^{[7]]}$ reported that INCB054329, when evaluated as monotherapy in a Phase I/II study (NCT02431260), required a second round of titration due to the high interpatient variability observed in clearance and exposure at different doses. However, the starting $20 \mathrm{mg}$ twice a day dose was not tolerated, and, unfortunately, several patients (MM participant included) discontinued treatment.

One other inhibitor, RO6870810, has been studied in a Phase I trial (NCT03068351). In the study, patients have reached pharmacokinetic (PK) exposures related to PD effects, displaying thrombocytopenia - a common side effect of BETi - but the final results are still being evaluated ${ }^{[72]}$.

As mentioned above, unfortunately, the success of BETis in the clinical setting has been limited so far, in part due to dose-limiting toxic effects. It should be noted that BETis also target key transcriptional networks controlled by tissue- and disease-specific enhancer regions, so that the transcriptional effects of BET inhibition are highly context-dependent ${ }^{[108]}$. Although many molecules of this class are being evaluated in Phase I/II clinical trials (e.g., CPI-0610 and RO6870810), they are clearly not considered as MYC inhibitors 
only. For a deeper analysis of the different studies in humans, as well as their NCT identifiers, refer to the following reviews ${ }^{[109-112]}$.

\section{Epigenetic inhibitors}

Chromatin modifiers such as histone methyltransferases have been defined as promising targets for many cancer types, including hematologic malignancies ${ }^{[113]}$, although not necessarily through MYC inhibition only. MYC, in particular, has been described to interact with chromatin complexes and to be able to induce epigenetic modifications. For instance, Tu et al. ${ }^{[114]}$ recently defined the G9a methyltransferase as one of MYC interactors. Similarly, EZH2 and DOT1L are other histone methyltransferases whose inhibition leads to MYC downregulation, resulting in tumor growth suppression through slightly different mechanisms $^{[115,116]}$.

In particular, EZH2 is involved in myeloma's pathogenesis and the acquisition of resistance to different drugs, and it is related to poor prognosis, raising interest in inhibiting it. Strong preclinical data support the translatability of this approach to a clinical setting ${ }^{[115]}$, including a recent report in which Ishiguro et al. ${ }^{[17]}$ showed that the dual EZH2/G9a inhibitor GSK126 exerted a potent tumor-suppressive effect by activating an immune response through upregulation of interferon (IFN) signaling and by halting the IRF4-MYC axis. In a separate earlier publication, the same authors showed that DOT1L inhibitors function in a very similar fashion, causing DNA damage that could explain the stimulation of IFN signaling, while shutting down the IRF4-MYC axis and thus blocking MM growth ${ }^{[73]}$. Interestingly, Dafflon et al. ${ }^{[75]}$ characterized the mechanism of action of SGC0946 and identified a subset of MM cell lines susceptible to it. In addition to the suppression of the IRF4-MYC axis, sensitive cells showed suppression of the TF ATF4, reduced global protein synthesis and alterations in the ER stress pathway ${ }^{[75]}$. In fact, panobinostat, a broad-spectrum histone deacetylase (HDAC) inhibitor, functions with almost the same mechanism of action, downregulating the mRNA of heme oxygenase-1, as well as IRF4 and MYC, causing the arrest of primary $\mathrm{CD} 138^{+}$patient cells and inducing their apoptosis ${ }^{[76]}$. Indeed, panobinostat is one of the few epigenetic drugs approved by the FDA for the treatment of $\mathrm{MM}^{[113]}$. Incidentally, Mondala et al. ${ }^{[78]}$ recently targeted IRF4 in MM as well, using instead an antisense oligonucleotide (ASO) and causing a decrease in MYC and MYC targets. Importantly, Mondala et al.$^{[78]}$ reported eradication of myeloma progenitors and malignant plasma cells and abrogation of tumor formation and disease dissemination in xenograft models while displaying no effect on normal human hematopoietic stem cells.

A very different type of molecule, RRx-001, was defined by its creators as a MYC inhibitor ${ }^{[118,119]}$ and "erythrophagoimmunotherapeutic". RRx-001 is also a novel hypoxia-selective epigenetic agent derived from the aerospace industry ${ }^{[120]}$. Its mechanism of action differs from that of the hypomethylating agents azacitidine or decitabine, in that RRx-001 causes oxidative stress under hypoxic conditions, inhibiting global hypermethylation and restoring tumor suppressor gene function ${ }^{[79]}$. It has been shown to exert antitumor activity in a myeloma xenograft model, both as monotherapy or in combination with standard antimyeloma agents (glucocorticoids or PIs) ${ }^{[79,80]}$. The authors describing it clarified that its antineoplastic efficacy is explained by a variety of mechanisms that include promoting an immune response, epigenetic modifications, apoptosis, antioxidant and antiangiogenic activities and acting as a nitric oxide donor ${ }^{[120]}$. Currently, this molecule seems to be mostly employed against solid tumors rather than hematological diseases.

Unfortunately, as standalone strategies, none of the above molecules performed in the clinical setting as predicted by preclinical studies. In a Phase I clinical trial, the investigators concluded that GSK126 is not a suitable EZH2 inhibitor to treat advanced solid or hematologic malignancies due to its improvable PK 
profile, leading to inefficient exposure at tolerated doses and displaying a minimal anticancer activity ${ }^{[74]}$. Similarly, Stein et al. ${ }^{[121]}$ evaluated the safety and efficacy of pinometostat in another Phase I study of acute mixed lineage leukemia and observed that, despite reaching exposure to anticancer levels, it could only display minor clinical activity, suggesting that its combination with standard of care agents would be a better choice. In support of this hypothesis, a recent Phase I study for the combination of panobinostat with several myeloma standard therapies demonstrated the ability of the combination to resensitize relapsed/refractory MM patients, in the context of resistance to IMiDs, PIs or other novel targets ${ }^{[77]}$. In addition, the IRF4 ASO will soon be tested in a first-in-human clinical trial as monotherapy for relapsed/refractory myeloma to assess its safety, tolerability and antimyeloma activity (NCT04398485).

\section{Cyclin-dependent kinase 7 or 9 inhibitors}

The blockade of cyclin-dependent kinase 7or 9 (CDK7 or CDK9) can also downregulate MYC expression and reduce mRNA levels by inhibiting RNA polymerase II-dependent transcription affecting the stability of preinitiation complexes ${ }^{[122]}$. Some studies demonstrated that THZ1, a covalent CDK7 inhibitor, can indeed suppress master transcription-regulating oncogenes, such as MYC, in neuroblastoma models ${ }^{[123,124]}$, and Zhang et al. ${ }^{[81]}$ expanded the study to several myeloma cell lines, reporting a potent antiproliferative and proapoptotic effect with exposure times as little as $24 \mathrm{~h}$ and even in the context of resistance to bortezomib. Mechanistically speaking, apart from MYC and DNA damage response genes (CtIP, FANCD2, RAD51, BRAC1 and ERCC1), the inhibitor diminished the expression of MCL-1 and BCL- $\mathrm{X}_{\mathrm{L}}$, in line with its expected function as a CDK7 and CDK12/13 inhibitor ${ }^{[81]}$. Notably, the authors demonstrated a reduction of subcutaneous xenograft tumors and extended survival of mice upon treatment with $10 \mathrm{mg} / \mathrm{kg}$ of THZ1 and suggested the combination with PIs or B-cell lymphoma 2 (Bcl-2) Homology 3 (BH-3) mimetics, as they observed a significant increase in cell death of primary patient-derived CD $138^{+}$cells and MM stem-like cells $\left(\mathrm{CD} 138^{-}, \mathrm{CD}_{19} 9^{+}, \mathrm{CD}_{20} \mathrm{O}^{+}, \mathrm{CD} 27^{+}\right)$, while having little effect on healthy cord blood cells $\left(\mathrm{CD} 138^{-}, \mathrm{CD} 34^{+}\right)^{[81]}$. In a brief article, Czudor et al. ${ }^{[82]}$ synthesized two novel CDK9 inhibitors that also displayed considerable antiproliferative effects in MM cell lines.

Thanks to the antitumor effect shown by these molecules at the preclinical stage, the first covalent CDK7 inhibitor (SY-1365) entered clinical trials in 2017 for the treatment of solid tumors ${ }^{[83]}$. Unfortunately, the study was terminated in March 2021 based on a business decision (NCT03134638). On a more encouraging note, however, the CDK9 inhibitor AZD4573 has been evaluated against a panel of hematologic cancer models, including cancer cell lines and cell line- and patient-derived xenografts, both subcutaneous and disseminated models. It demonstrated a similar mechanism of action to that shown for THZ1, depleting MCL- $1^{[84]}$. The definition of the PK/PD/efficacy model helped inform the currently ongoing clinical trial design to assess the safety, tolerability, PK and preliminary anticancer activity of this molecule against relapsed/refractory hematologic malignancies (NCT03263637).

In any case, how much of the therapeutic impact of the above-mentioned drugs is due specifically to MYC inhibition remains to be established.

\section{Blockade of MYC mRNA translation}

\section{Mammalian target of rapamycin and PI3K inhibitors}

Mammalian target of rapamycin (mTOR) seems to play an essential role in the translation of MYC $\mathrm{mRNA}^{[125]}$, among others, laying the foundations for inhibiting the PI3K/mTOR pathway as another possible strategy to indirectly inhibit MYC. Indeed, several drugs have already been approved (e.g., everolimus, temsirolimus and torkinib), and some others are in earlier clinical developmental stages (e.g., INK128) ${ }^{[126]}$. Interestingly, the dual PI3K/HDAC inhibitor CUDC-907 showed potent suppressive activity 
against MYC-dependent tumors ${ }^{[85,127]}$, and, in a Phase II study assessing its safety (NCT02674750), 14\% of evaluable relapsed/refractory lymphoma patients achieved an objective clinical response ${ }^{[85]}$.

In this same context, Paíno et al. ${ }^{\left[{ }^{[8]}\right.}$ presented a pan-PIM kinase inhibitor, PIM447, able to block all three PIM kinases and act as an mTOR inhibitor, which exhibited cytotoxic effects on myeloma cells and a boneprotective effect in a disseminated mouse model of human myeloma. Interestingly, the authors also reported the decrease of MYC levels and the increased expression of MAD-1, a MYC antagonist. In line with what others proposed for different small-molecule inhibitors, the authors demonstrated a strong synergistic effect with standard of care agents (IMiDs and PIs), supporting the use of this combination to treat MM patients ${ }^{[86]}$. In fact, in a more recent publication, the same authors used one of these combinations (PIM447 plus pomalidomide and dexamethasone) and showed improved survival in a preclinical mouse model, where they revealed a convergent blockage of MYC and mTORC1, disrupting the function of eIF4e (Eukaryotic translation Initiation Factor $4 \mathrm{E}$ ), an essential element of the Initiation Translation Complex ${ }^{[128]}$, and downregulating IRF4, important in many immune-related contexts ${ }^{[29]}$, as happened with several $\mathrm{BETi}^{[87]}$. Interestingly, Buettner et al. ${ }^{[89]}$ presented a similar effect by leflunomide, an orally available, nontoxic, inexpensive immunosuppressive drug regularly used to treat rheumatoid arthritis. Leflunomide downregulated MYC by inhibiting several tyrosine kinases, including the PIM family, and synergized in combination with lenalidomide, another IMiD used as standard therapy in MM, further decreasing MYC and causing MM growth inhibition both in vitro and in vivo ${ }^{[89]}$.

The first-in-human trial to determine the maximum-tolerated dose (MTD) or recommended dose, safety, PK and preliminary antimyeloma activity of PIM447 in relapsed/refractory myeloma showed that the compound was tolerated by heavily pretreated patients and clinically benefitted $25.3 \%$ of the study population (even though most of the discontinuations were due to disease progression) ${ }^{[88]}$. Of note, the investigators could not evaluate the PD markers identified in preclinical studies (phospho-Bad, phospho4EBP1 and c-MYC) because of the absence of clinically valid assays ${ }^{[88]}$. Encouragingly, the progression-free survival seen as monotherapy, together with the preclinical evidence supporting the combination of several agents, builds the case for combining PIM447 with other targeted therapies to overcome drug resistance in patients ${ }^{[88]}$.

Of note, a Phase I clinical trial was also designed to repurpose the use of leflunomide in relapsed/refractory myeloma patients (NCT02509052) ${ }^{\left[{ }^{[0]}\right.}$. As stated by Rosenzweig et al. ${ }^{[00]}$, given the stable disease achieved in 9/11 subjects, coupled with the tolerable safety profile, leflunomide could be another option for combinatorial regimens to treat MM or, if introduced at earlier developmental stages (SMM) of the disease, delay its progression into the fully malignant one.

\section{Blocking eukaryotic translation initiation factors or nuclear export of $m R N A$}

Selinexor is an oral selective exportin 1 (XPO1) inhibitor that causes tumor suppression of several cancer models through different mechanisms. One of them is the impairment of the nuclear export of tumor suppressor and growth regulatory proteins, such as p53 or MYC, respectively ${ }^{[130]}$. In addition, it has been shown to reduce the cap-dependent translation of several oncogenes, including $\mathrm{MYC}^{[130]}$.

Vogl et al. ${ }^{[91]}$ tested selinexor in combination with low-dose dexamethasone in relapsed or refractory myeloma patients. In this Phase II trial, patients were either quad-refractory (bortezomib, carfilzomib, pomalidomide and lenalidomide refractory disease) or penta-refractory (anti-CD38 refractory disease) ${ }^{[91]}$. The overall response rate (the primary endpoint) was $21 \%$, very similar in the quad- and penta-refractory patients' cohorts, providing the latter with a new treatment option. Following the same trend, the authors 
suggested using selinexor in combination with other standard antimyeloma agents, with the objective of overcoming or at least reducing the appearance of drug resistance ${ }^{[91]}$. Indeed, a couple of randomized Phase II/III trials sponsored by Karyopharm Therapeutics Inc. are currently evaluating the efficacy of the abovementioned combinations (NCT03110562 and NCT04414475).

Rocaglates are secondary metabolites of the plant genus Aglaia. These compounds inhibit eIF4A, impeding translation initiation. Maïga et al. ${ }^{[97]}$ studied the potency of the synthetic derivative oxo-aglaiastatin (CMLD011580) to inhibit translation and synergize with other compounds against hematologic tumors. CMLD011580 induced cell death of JJN3 and MMS1, two myeloma cell lines, upon combined treatment with ABT-199, a BCL-2 inhibitor. Importantly, the authors showed how the agaliastatin analog could block MYC mRNA translation and synergize with the glucocorticoid dexamethasone (as previously shown by the same group with another rocaglate, silvestrol), inducing cytotoxic effects in MM cell lines. In addition, they explored the effect on primary patient-derived cells, demonstrating a considerable reduction in CD138 $8^{+}$ cells $^{[97]}$. Despite their apparent applicability as anticancer agents, no current clinical trials are dedicated to studying this therapeutic approach. However, they are being investigated as broad-spectrum antivirals, thanks to their unique mechanism of action and minimal potential toxic side effects while inducing efficient inhibition of RNA viruses ${ }^{[131]}$.

Once again, since all the above-mentioned drugs affect translation of many more proteins besides MYC, ascribing their therapeutic effect to MYC only would be incorrect.

\section{Promoting MYC degradation}

MYC is ubiquitinated by ubiquitin ligases, such as FBW7, which induce its degradation through the proteasome machinery. Inhibition of deubiquitinases that stabilize MYC (e.g., USP28 and USP 36$)^{[132]}$ or triggering the FBW7-mediated proteasomal degradation of MYC with oridonin ${ }^{[133]}$ are both potential strategies to indirectly inhibit MYC.

In this context, Grieve et al. ${ }^{[98]}$ discovered an unexpected role of the TAZ, a transcriptional coactivator, component of the Hippo-signaling pathway, described to function as an oncogene in many solid cancers, but found to act as a tumor suppressor in myeloma: TAZ expression inversely correlated with the prognostic outcome in myeloma patients. Indeed, Grieve et al. ${ }^{[98]}$ demonstrated that restoring TAZ using lentiviruses in vitro or pharmacologically upregulating it by treating cells with a hypomethylating drug (DAC) resulted in MM cell death. They also pinpointed the underlying molecular mechanism in the downregulation of MYC at different levels (transcriptomic, proteomic and posttranslational), resulting in the observed antiproliferative effect. Although the exact mechanisms for MYC loss remain elusive, understanding the TAZ-mediated regulation of MYC, especially posttranslationally, could produce valuable information on potential combinations involving the upregulation of TAZ with anti-MYC therapies ${ }^{[8]}$.

Another means to cause MM cell death and overcome bortezomib resistance was described by Ronca et al. ${ }^{[99]}$, showing that FGF/FGFR blockade by the pan-FGF trap molecule NSC12 induces mitochondrial oxidative stress and DNA damage. In particular, mitochondrial oxidative stress occurred as a consequence of proteasomal degradation of the c-MYC oncoprotein, which caused glutathione depletion. The authors reported two clinical trials assessing selective TK FGFR inhibitors, erdafitinib and AZD4547, one ongoing and one just completed (NCT03732703 and NCT04439240). It would be interesting to know their effect on tumor MYC levels ${ }^{[99]}$. 
Yao et al. ${ }^{[101]}$ found 7594-0037, which also led to cell death of MM cells, in a screen of the ChemiDev database in search of MYC inhibitors and showed that 7594-0037 induced MYC degradation by reducing its phosphorylation on serine 62. In addition, the molecule further decreased the MYC intrinsic lack of stability by binding to the $\mathrm{N}$-terminus, preventing the $\mathrm{C}$ - and $\mathrm{N}$-termini from interacting ${ }^{[101]}$. The authors showed how treatment with 7594-0037 induced cell cycle arrest in $\mathrm{G}_{2} / \mathrm{M}$ in RPMI-8226 and U266 cells, promoting apoptotic death, as seen by an increase in PARP1, caspase- 8 and caspase- 9 cleavage. The compound demonstrated also synergistic effects with bortezomib, supporting its use to overcome resistance. Yao et al. ${ }^{[101]}$ suggested that this approach has the potential to be translated into the clinical setting. However, extensive research is still required, starting with evaluating the therapeutic impact in animal models, as well as the bioavailability and PK of the compound, to decide whether it is worth pursuing further.

A completely different drug, yet with a similar mechanism of action, is anlotinib (AL3818), a multi-targeting tyrosine kinase inhibitor directed against vascular endothelial growth factor receptor (VEGFR) 1-3, c-Kit, platelet-derived growth factor receptor (PDGFR)- $\alpha / \beta$ and fibroblast growth factor receptor (FGFR) ${ }^{[102]}$. Cao et al. ${ }^{[102]}$ showed the accumulation of RPMI-8226, NCI-H929 and primary patient-derived cells in $\mathrm{G}_{2} / \mathrm{M}$ phase upon treatment with anlotinib, reporting apoptotic cell death seen by cleavage of PARP1 and caspases 3 and 9. Notably, the authors reported the direct interaction of anlotinib with the oncoprotein MYC, leading to its ubiquitin proteasome-mediated degradation, which is triggered by dephosphorylation of serine 62 and phosphorylation of threonine 58. Efficacy was also observed in an in vivo subcutaneous xenograft model, in which anlotinib significantly impaired tumor growth, reducing the proliferative marker Ki67 and increasing TUNEL and caspase-3-positive cells ${ }^{[102]}$. This interaction is a new aspect of the inhibitor so far unexplored that sets the rationale for using this inhibitor to treat MYC-deregulated cancers. Hitherto, no clinical trial is approved to evaluate anlotinib against hematologic cancers, although it is being studied for several other indications ${ }^{[103]}$.

Finally, another reported strategy to induce MYC degradation makes use of mTOR inhibition (as already mentioned in this manuscript as a potential way of preventing MYC translation) in combination with HDAC inhibition. Indeed, Simmons et al. ${ }^{[104]}$ made us of mTORi (rapamycin) and HDACi (MS275/entinostat) inhibitors in myeloma, reducing MYC protein stability and causing a significant anti-tumor effect. Simmons et al. ${ }^{[104]}$ suggested that the combined use of drug classes that have separately already entered clinical practice as single agents could represent a promising strategy to inhibit MYC.

\section{Direct MYC inhibitors}

As mentioned above, the MYC protein is hard to target with traditional small molecule drugs due to its large, disordered protein interface and lack of deep pockets. In addition, it is often inaccessible to large biologics, which are not always capable of crossing cell membranes.

\section{Direct inhibition of MYC expression}

G-quadruplex stabilization

G-quadruplexes are four-stranded DNA structures formed in guanine-rich regions. The MYC promoter happens to have such a structure, which acts as a silencer element, repressing its transcription ${ }^{[134]}$. Several studies have shown that some small-molecule ligands (e.g., cationic porphyrins and quindolines) can stabilize such G-quadruplex. The first one was CX-3543, which was shown to reduce MYC transcription ${ }^{[135,136]}$. Subsequently, a more selective RNA polymerase I inhibitor, termed CX-5461, demonstrated the ability to be used in vivo ${ }^{[137]}$. This compound was even evaluated in a Phase I study for advanced hematologic malignancies and was well tolerated. The predominant population of patients corresponded to myeloma, whose best response was stable disease in half of the $\operatorname{cases}^{[138]}$. More recently, 
Leung et al. ${ }^{[139]}$ proposed a novel liposomal formulation of CX-5461 that could result in exposure to higher concentrations of the drug over time, potentially increasing its efficacy.

Others have identified different small molecules that act as MYC G4-stabilizers, such as DC-34 ${ }^{[140]}$, Do89 $9^{[141]}$ or DM039 ${ }^{[142]}$. Calabrese et al. ${ }^{[140]}$ explored the effects of DC-34 in MM cell lines, observing that the compound did not downregulate other G4-dependent genes to the same extent as MYC, which was efficiently silenced, with consequent antiproliferative activity. On their end, Gaikwad et al. ${ }^{[141]}$ described a cytotoxic effect of D089 in myeloma cells regardless of their protective microenvironment when cocultured with bone marrow stromal cells, and such death occurred through the activation of the ER stress pathway leading to pyroptosis and senescence ${ }^{[141]}$.

Antisense oligonucleotides and small interfering RNA

A different strategy to inhibit MYC's expression is to promote the degradation of its mRNA, thus preventing its translation. For this purpose, investigators have used antisense oligonucleotides (INX$3280)^{[143]}$ or antisense oligomers (AVI-4126) ${ }^{[144]}$.

With a similar mode of inhibition, the lentiviral delivery of shRNA ${ }^{[145]}$ or RNAi encapsulated in a lipid nanoparticle (DCR-MYC) ${ }^{[146]}$ can also result in the elimination of MYC mRNA. Even though DCR-MYC reached clinical trials, the efficacy results obtained did not fulfill the company's expectations, thus its development was ultimately discontinued (NCT02110563).

In Table 2, we have summarized the most recent studies, mostly preclinical, about direct MYC inhibitors in hematologic malignancies, particularly MM.

\section{Direct inhibition of PPIs or DNA binding}

Peptidomimetics and other small molecule inhibitors against PPIs

Peptidomimetics are small molecules designed to mimic the binding of a peptide sequence to a target ${ }^{[149]}$. The first inhibitor of the MYC/MAX interaction, ILA6B17, was identified after screening a 7000-molecule peptidomimetic library and suppressed the growth of MYC-transformed chicken embryo fibroblasts (although it was suggested to be slightly unspecific, since it could also inhibit Jun-induced transformation) ${ }^{[150]}$. Other compounds have been identified by multiple different screenings as being more MYC-specific (e.g., 10058-F4, 10074-G5, Mycro3 or KJ-Pyr-9) ${ }^{[151-154]}$. However, there are no recent studies that investigate the therapeutic opportunity of these molecules in hematologic cancers, despite their great promise, leaving the door open for new compounds to be tested.

\section{DNA binding inhibitors}

Some research groups have instead targeted the binding of MYC, MAX or their dimers, to DNA, using small molecules such as MYRA-A or KSI-3716 $6^{[155,156]}$ or peptides and mini-proteins, known to have increased selectivity and affinity, as well as lower toxicity. An example of the latter is H1, a 14-amino acid peptide derived from the helix 1 C-terminal region of MYC itself ${ }^{[157]}$. Our group contributed to the effort using the purified Omomyc mini-protein, shifting the use of Omomyc from transgenic construct to a pharmacological tool ${ }^{[158]}$.

The intravenous formulation of Omomyc, OMO-103 is currently being tested in a Phase I/II clinical trial (NCT04808362) for solid tumors. However, its use or the use of similar molecules could be extended to treat blood cancers. 
Table 2. Summary of the different direct MYC inhibitors and their development stage for hematological tumors (focused on MM)

\begin{tabular}{|c|c|c|c|c|c|}
\hline $\begin{array}{l}\text { Class of } \\
\text { inhibitor }\end{array}$ & Name & $\begin{array}{l}\text { Combined with } \\
\text { other } \\
\text { therapies? }\end{array}$ & Mechanism of action & Clinical trials & Ref. \\
\hline \multirow[t]{4}{*}{$\begin{array}{l}\text { G4- } \\
\text { quadruplex } \\
\text { stabilizers }\end{array}$} & $C X-5461$ & No & $\begin{array}{l}\text { Reduction of } M Y C \\
\text { transcription }\end{array}$ & $\begin{array}{l}\text { Beneficial clinical responses in some } \\
\text { cases and MTD determination } \\
\text { (ACTRN12613001061729) }\end{array}$ & Khot et al. ${ }^{[138]}$ \\
\hline & DC-34 & No & & Preclinical & Calabrese et al. ${ }^{[140]}$ \\
\hline & D089 & No & & Preclinical & Gaikwad et al. $^{[141]}$ \\
\hline & DMO039 & No & & Preclinical & Minard et al. ${ }^{[142]}$ \\
\hline siRNA & DCR-MYC & No & Elimination of MYC mRNA & $\begin{array}{l}\text { Terminated (sponsor decision) } \\
\text { (NCT02110563) }\end{array}$ & Tolcher et al. ${ }^{[146]}$ \\
\hline $\begin{array}{l}\text { PPI or DNA } \\
\text { binding } \\
\text { inhibitors }\end{array}$ & & No & $\begin{array}{l}\text { Blockade of the interaction } \\
\text { of MYC with partners } \\
\text { (mainly MAX) or with } \\
\text { DNA }\end{array}$ & No recent updates in the clinical setting & \\
\hline \multirow[t]{2}{*}{$\begin{array}{l}\text { Synthetic } \\
\text { lethality }\end{array}$} & $\begin{array}{l}\text { LNA gapmR } \\
\text { ASO } \\
\text { (MIR17PTi) }\end{array}$ & No & $\begin{array}{l}\text { Upregulation of BIM by } \\
\text { targeting miR-17-92s }\end{array}$ & Preclinical & Morelli et al. ${ }^{[147]}$ \\
\hline & PARPi & & Addiction to PARP1 & Preclinical & Caracciolo et al. ${ }^{[148]}$ \\
\hline
\end{tabular}

siRNA: Small interfering RNA; MM: multiple myeloma; MTD: maximum-tolerated dose; PPI: protein-protein interaction.

\section{MYC-dependent synthetic lethality}

MYC is a key transcriptional regulator of many genes, including micro-RNAs such as miR-17-92, involved in maintaining cellular homeostasis during MYC-driven tumorigenesis, suppressing the apoptotic program led by the oncoprotein. In this context, Morelli et al ${ }^{[147]}$ hypothesized that inhibition of these miRNAs could be synthetic lethal in MYC-deregulated tumors, such as $\mathrm{MM}^{[147,159]}$. The authors used LNA gapmeR antisense oligonucleotides to target all six miR-17-92s. They focused on one particular ASO, MIR17PTi, and demonstrated a robust effect in a relevant preclinical in vivo model ${ }^{[147]}$. As for the mechanism underlying the synthetic lethality, the authors noted some resistant cell lines that lacked the expression of the tumor suppressor BIM, speculating that feed-forward loops between MYC and miR-17-92 were required to induce the upregulation of BIM (and other genes) that would trigger apoptosis in this particular context, in which oncogenic MYC controls the apoptotic program ${ }^{[147]}$. Despite the thorough characterization of this new strategy, including PK profiles in non-human primates, a well-defined mechanism of action and impactful antimyeloma effect, to our knowledge, there is no planned clinical study to explore such a compelling alternative yet.

Another attractive investigational area for synthetic lethality is the DNA damage response, as cancer cells are addicted to compensatory DNA repair pathways. Indeed, Caracciolo et al. ${ }^{[148]}$ highlighted the potential of using PARP inhibition in MM, in particular in the case of bortezomib resistance, pointing to a new role of MYC in driving PARP-1 mediated repair. Caracciolo et al. ${ }^{[148]}$ elegantly explained how MYC contributes to genomic instability, switching the preferential DNA repair mechanisms to the error-prone PARP-mediated alternative non-homologous end joining, and pointed to its potential use as a predictive biomarker for PARPi treatments in $\mathrm{MM}^{[148]}$.

\section{CONCLUSION}

In this review, we try to compile the most recent publications describing the use of different MYC inhibitors in hematologic malignancies, especially MM. 
The first attempts to use this strategy in the clinic, unfortunately, have not shown much efficacy (INCB054329, GSK126, SY-1365 and DCR-MYC). Nevertheless, a few are proposed to have potential for improved activity when combined with standard antimyeloma therapies (pinometostat, PIM447, leflunomide, selinexor and TAZ-upregulation). For some compounds, we need to report the lack of follow up or publications of recent results in the last years (CX-5461, peptidomimetic inhibitors and other direct MYC inhibitors, such as biologics including peptides and mini-proteins). On a more positive note, however, many of the molecules reviewed here are still being evaluated in clinical trials (RO6870810, IRF4 ASO and AZD4573) or have a strong enough rationale and preclinical evidence to inform the design of clinical trials for their assessment (rocaglates, new BETi, anlotinib, DC-34, D089 and synthetic lethality strategies), giving us some hope that we will eventually see positive clinical outcome.

One aspect that seems clear from most of the studies is that the field of MM has reached a consensus in preferring combinatorial approaches, above all in the relapsed/refractory context. By targeting different aspects of MM cell biology, many of which are ultimately controlled by MYC, the research community expects to achieve higher response rates, delay resistance appearance and resensitize patients who have exhausted all other alternatives, attempting to prolong survival and ultimately getting one step closer to rendering myeloma a curable disease.

\section{DECLARATIONS}

\section{Acknowledgments}

Martínez-Martín S thanks the Generalitat de Catalunya for the FI-DGR predoctoral grant FI_B2 00187. Research in our laboratories was supported by the Retos-Colaboración [RTC2019-007067-1] grant from the Spanish Ministry of Economy and Competitiveness. Figures 2-4 have been created with Biorender.com.

\section{Authors' contributions}

Conceptualization, investigation, writing: Martínez-Martín S

Conceptualization, supervision, writing: Soucek L

\section{Availability of data and materials}

Not applicable.

\section{Financial support and sponsorship}

None.

\section{Conflicts of interest}

Soucek L is founder and shareholder of Peptomyc S.L. and inventor of patent application WO2014180889 A 8 that covers the use of the Omomyc mini-protein in medicine, held by VHIO and licensed to Peptomyc. Martínez-Martín S declared that there are no conflicts of interest.

\section{Ethical approval and consent to participate}

Not applicable.

\section{Consent for publication}

Not applicable.

\section{Copyright}

(c) The Author(s) 2021. 


\section{REFERENCES}

1. Kazandjian D. Multiple myeloma epidemiology and survival: A unique malignancy. Semin Oncol 2016;43:676-81. DOI PubMed PMC

2. GLOBOCAN. Cancer Today. Estimated number of new cases in 2020, WHO Europe (EURO), both sexes, all ages. Available from: https://gco.iarc.fr/today/online-analysis-table?v=2020\&mode=cancer\&mode_population=continents\&population$=900 \&$ populations $=994 \& \mathrm{key}=$ asr \&se $=0 \&$ cancer $=39 \&$ type $=0 \&$ statistic $=5 \&$ prevalence $=0 \&$ population_group $=0 \&$ ages_group $\% 5 \mathrm{~B} \%$ 5D=0\&ages_group $\% 5 \mathrm{~B} \% 5 \mathrm{D}=17$ \&group_cancer=0\&include_nmsc $=1 \&$ include_nmsc_other $=1$. [Last accessed on 19 Aug 2021].

3. GLOBOCAN. Cancer Today. Estimated number of new cases in 2020, worldwide, both sexes, all ages. Available from: https://gco.iarc.fr/today/online-analysis-table? $\mathrm{v}=2020 \&$ mode $=$ cancer\&mode_population=continents\&population$=900 \&$ populations $=900 \& \mathrm{key}=$ asr \&se $=0 \&$ cancer $=39 \&$ type $=0 \&$ statistic $=5 \&$ prevalence $=0 \&$ population_group $=0 \&$ ages_group $\% 5 \mathrm{~B} \%$ $5 \mathrm{D}=0$ \&ages_group $\% 5 \mathrm{~B} \% 5 \mathrm{D}=17$ \&group_cancer $=0 \&$ include_nmsc $=1 \&$ include_nmsc_other $=1$. [Last accessed on 19 Aug 2021].

4. Kumar SK, Rajkumar V, Kyle RA, et al. Multiple myeloma. Nat Rev Dis Primers 2017;3:17046. DOI PubMed

5. de la Puente P, Azab AK. Nanoparticle delivery systems, general approaches, and their implementation in multiple myeloma. Eur $J$ Haematol 2017;98:529-41. DOI PubMed PMC

6. Kurtin SE. Relapsed or relapsed/refractory multiple myeloma. J Adv Pract Oncol 2013;4:5-14.

7. Ravi P, Kumar SK, Cerhan JR, et al. Defining cure in multiple myeloma: a comparative study of outcomes of young individuals with myeloma and curable hematologic malignancies. Blood Cancer J 2018;8:26. DOI PubMed PMC

8. Cancer Research UK, Myeloma incidence statistics 2016. Available from: https://www.cancerresearchuk.org/healthprofessional/cancer-statistics/statistics-by-cancer-type/myeloma/incidence. [Last accessed on 19 Aug 2021].

9. GLOBOCAN. Cancer Tomorrow. Estimated number of new cases from 2020 to 2040, Both sexes, age [0-85+] Multiple myeloma and immunoproliferative diseases World. Available from: https://gco.iarc.fr/tomorrow/en/dataviz/isotype?cancers=35\&single_unit=5 0000 \&years $=2040 \&$ group_populations $=0 \&$ multiple_populations $=0 \&$ group_cancers $=0 \&$ multiple_cancers $=0$. [Last accessed on 19 Aug 2021].

10. Manier S, Salem KZ, Park J, Landau DA, Getz G, Ghobrial IM. Genomic complexity of multiple myeloma and its clinical implications. Nat Rev Clin Oncol 2017;14:100-13. DOI PubMed

11. Landgren O, Kyle RA, Pfeiffer RM, et al. Monoclonal gammopathy of undetermined significance (MGUS) consistently precedes multiple myeloma: a prospective study. Blood 2009;113:5412-7. DOI PubMed PMC

12. Kyle RA, Therneau TM, Rajkumar SV, et al. A long-term study of prognosis in monoclonal gammopathy of undetermined significance. N Engl J Med 2002;346:564-9. DOI PubMed

13. Kyle RA, Remstein ED, Therneau TM, et al. Clinical course and prognosis of smoldering (asymptomatic) multiple myeloma. $N$ Engl J Med 2007;356:2582-90. DOI PubMed

14. Kovalchuk AL, Mushinski EB, Janz S. Clonal diversification of primary BALB/c plasmacytomas harboring T(12;15) chromosomal translocations. Leukemia 2000;14:909-21. DOI PubMed

15. Walker BA, Mavrommatis K, Wardell CP, et al. Identification of novel mutational drivers reveals oncogene dependencies in multiple myeloma. Blood 2018;132:587-97. DOI PubMed PMC

16. Jovanović KK, Roche-Lestienne C, Ghobrial IM, Facon T, Quesnel B, Manier S. Targeting MYC in multiple myeloma. Leukemia 2018;32:1295-306. DOI PubMed

17. Dib A, Gabrea A, Glebov OK, Bergsagel PL, Kuehl WM. Characterization of MYC translocations in multiple myeloma cell lines. $J$ Natl Cancer Inst Monogr 2008:25-31. DOI PubMed PMC

18. Weinhold N, Ashby C, Rasche L, et al. Clonal selection and double-hit events involving tumor suppressor genes underlie relapse in myeloma. Blood 2016;128:1735-44. DOI PubMed PMC

19. Terpos E, Ntanasis-Stathopoulos I, Gavriatopoulou M, Dimopoulos MA. Pathogenesis of bone disease in multiple myeloma: from bench to bedside. Blood Cancer J 2018;8:7. DOI PubMed PMC

20. Garcia-Gomez A, Sanchez-Guijo F, Del Cañizo MC, San Miguel JF, Garayoa M. Multiple myeloma mesenchymal stromal cells: contribution to myeloma bone disease and therapeutics. World J Stem Cells 2014;6:322-43. DOI PubMed PMC

21. Higgs JT, Lee JH, Wang H, et al. Mesenchymal stem cells expressing osteoprotegerin variants inhibit osteolysis in a murine model of multiple myeloma. Blood Adv 2017;1:2375-85. DOI PubMed PMC

22. Chae YK, Pan AP, Davis AA, et al. Path toward precision oncology: review of targeted therapy studies and tools to aid in defining "actionability" of a molecular lesion and patient management support. Mol Cancer Ther 2017;16:2645-55. DOI PubMed

23. Badalian-Very G. Personalized medicine in hematology - a landmark from bench to bed. Comput Struct Biotechnol J 2014;10:70-7. DOI PubMed PMC

24. Schwartzberg L, Kim ES, Liu D, Schrag D. Precision oncology: who, how, what, when, and when not? Am Soc Clin Oncol Educ Book 2017;37:160-9. DOI PubMed

25. Shin SH, Bode AM, Dong Z. Precision medicine: the foundation of future cancer therapeutics. NPJ Precis Oncol 2017;1:12. DOI PubMed PMC

26. Hantschel O, Rix U, Superti-Furga G. Target spectrum of the BCR-ABL inhibitors imatinib, nilotinib and dasatinib. Leuk Lymphoma 2008;49:615-9. DOI PubMed

27. Bhullar KS, Lagarón NO, McGowan EM, et al. Kinase-targeted cancer therapies: progress, challenges and future directions. Mol Cancer 2018;17:48. DOI PubMed PMC

28. NIH NCI. Targeted cancer therapies. Available from: https://www.cancer.gov/about-cancer/treatment/types/targeted- 
therapies/targeted-therapies-fact-sheet\#what-targeted-therapies-have-been-approved-for-specific-types-of-cancer. [Last accessed on 19 Aug 2021].

29. Rossi JF. Targeted therapies in adult B-cell malignancies. Biomed Res Int 2015;2015:217593. DOI PubMed PMC

30. Fabbro D, Cowan-Jacob SW, Moebitz H. Ten things you should know about protein kinases: IUPHAR Review 14. Br J Pharmacol 2015;172:2675-700. DOI PubMed PMC

31. Balik K, Modrakowska P, Maj M, Kaźmierski Ł, Bajek A. Limitations of molecularly targeted therapy. Medical Research Journal 2019;4:99-105. DOI

32. Wallington-Beddoe CT, Sobieraj-Teague M, Kuss BJ, Pitson SM. Resistance to proteasome inhibitors and other targeted therapies in myeloma. Br J Haematol 2018;182:11-28. DOI PubMed

33. Sabnis AJ, Bivona TG. Principles of resistance to targeted cancer therapy: lessons from basic and translational cancer biology. Trends Mol Med 2019;25:185-97. DOI PubMed PMC

34. Hann SR. MYC cofactors: molecular switches controlling diverse biological outcomes. Cold Spring Harb Perspect Med 2014;4:a014399. DOI PubMed PMC

35. Barrett J, Birrer MJ, Kato GJ, Dosaka-akita H, Dang CV. Activation domains of L-Myc and c-Myc determine their transforming potencies in rat embryo cells. Mol Cell Biol 1992;12:3130-7. DOI PubMed PMC

36. Nesbit CE, Grove LE, Yin X, Prochownik EV. Differential apoptotic behaviors of c-myc, N-myc, and L-myc oncoproteins. Cell Growth Differ 1998;9:731-41. PubMed

37. Dang CV. MYC on the path to cancer. Cell 2012;149:22-35. DOI PubMed PMC

38. Stefan E, Bister K. MYC and RAF: key effectors in cellular signaling and major drivers in human cancer. In: Hunter E, Bister K, editors. Viruses, genes, and cancer. Cham: Springer International Publishing; 2017. p. 117-51.

39. Nasi S, Ciarapica R, Jucker R, Rosati J, Soucek L. Making decisions through Myc. FEBS Letters 2001;490:153-62. DOI PubMed

40. Soucek L, Evan GI. The ups and downs of Myc biology. Curr Opin Genet Dev 2010;20:91-5. DOI PubMed PMC

41. Conacci-Sorrell M, McFerrin L, Eisenman RN. An overview of MYC and its interactome. Cold Spring Harb Perspect Med 2014;4:a014357. DOI PubMed PMC

42. Stine ZE, Walton ZE, Altman BJ, Hsieh AL, Dang CV. MYC, metabolism, and cancer. Cancer Discov 2015;5:1024-39. DOI PubMed PMC

43. Davis AC, Wims M, Spotts GD, Hann SR, Bradley A. A null c-myc mutation causes lethality before 10.5 days of gestation in homozygotes and reduced fertility in heterozygous female mice. Genes Dev 1993;7:671-82. DOI PubMed

44. Schaub FX, Dhankani V, Berger AC, et al; Cancer Genome Atlas Network. Pan-cancer alterations of the MYC oncogene and its proximal network across the cancer genome atlas. Cell Syst 2018;6:282-300.e2. DOI PubMed PMC

45. Gabay M, Li Y, Felsher DW. MYC activation is a hallmark of cancer initiation and maintenance. Cold Spring Harb Perspect Med 2014;4:a014241. DOI PubMed PMC

46. Dhillon P, Evan G. In conversation with Gerard Evan. FEBS J 2019;286:4824-31. DOI PubMed

47. Dominguez-Sola D, Gautier J. MYC and the control of DNA replication. Cold Spring Harb Perspect Med 2014;4:a014423. DOI PubMed PMC

48. Sabò A, Amati B. Genome recognition by MYC. Cold Spring Harb Perspect Med 2014;4:a014191. DOI PubMed PMC

49. Hanahan D, Weinberg RA. Hallmarks of cancer: the next generation. Cell 2011;144:646-74. DOI PubMed

50. Tannock I, Hill R, Bristow R, Harrington L. The basic science of oncology. 5th ed: McGraw-Hill Professional; 2013. p. 588.

51. Holien T, Misund K, Olsen OE, et al. MYC amplifications in myeloma cell lines: correlation with MYC-inhibitor efficacy. Oncotarget 2015;6:22698-705. DOI PubMed PMC

52. Felsher DW, Bishop J. Reversible tumorigenesis by MYC in hematopoietic lineages. Molecular Cell 1999;4:199-207. DOI PubMed

53. Pelengaris S, Littlewood T, Khan M, Elia G, Evan G. Reversible activation of c-Myc in skin. Molecular Cell 1999;3:565-77. DOI PubMed

54. Giuriato S, Rabin K, Fan AC, Shachaf CM, Felsher DW. Conditional animal models: a strategy to define when oncogenes will be effective targets to treat cancer. Semin Cancer Biol 2004;14:3-11. DOI PubMed

55. Arvanitis C, Felsher DW. Conditionally MYC: insights from novel transgenic models. Cancer Lett 2005;226:95-9. DOI PubMed

56. Jain M, Arvanitis C, Chu K, et al. Sustained loss of a neoplastic phenotype by brief inactivation of MYC. Science 2002;297:102-4. DOI PubMed

57. Pelengaris S, Khan M, Evan GI. Suppression of Myc-induced apoptosis in $\beta$ cells exposes multiple oncogenic properties of Myc and triggers carcinogenic progression. Cell 2002;109:321-34. DOI PubMed

58. Marinkovic D, Marinkovic T, Mahr B, Hess J, Wirth T. Reversible lymphomagenesis in conditionally c-MYC expressing mice. Int $J$ Cancer 2004;110:336-42. DOI PubMed

59. Soucek L, Whitfield J, Martins CP, et al. Modelling Myc inhibition as a cancer therapy. Nature 2008;455:679-83. DOI PubMed PMC

60. Soucek L, Whitfield JR, Sodir NM, et al. Inhibition of Myc family proteins eradicates KRas-driven lung cancer in mice. Genes Dev 2013;27:504-13. DOI PubMed PMC

61. Dang CV, Reddy EP, Shokat KM, Soucek L. Drugging the 'undruggable' cancer targets. Nat Rev Cancer 2017;17:502-8. DOI PubMed PMC

62. Whitfield JR, Beaulieu ME, Soucek L. Strategies to inhibit Myc and their clinical applicability. Front Cell Dev Biol 2017;5:10. DOI PubMed PMC

63. Soucek L, Jucker R, Panacchia L, Ricordy R, Tatò F, Nasi S. Omomyc, a potential Myc dominant negative, enhances Myc-induced 
apoptosis. Cancer Res 2002;62:3507-10. PubMed

64. Savino M, Annibali D, Carucci N, et al. The action mechanism of the Myc inhibitor termed Omomyc may give clues on how to target Myc for cancer therapy. PLoS One 2011;6:e22284. DOI PubMed PMC

65. Massó-Vallés D, Soucek L. Blocking Myc to treat cancer: reflecting on two decades of Omomyc. Cells 2020;9:883. DOI PubMed PMC

66. Koh CM, Sabò A, Guccione E. Targeting MYC in cancer therapy: RNA processing offers new opportunities. Bioessays 2016;38:26675. DOI PubMed PMC

67. Gu J, Song S, Han H, et al. The BET bromodomain inhibitor OTX015 synergizes with targeted agents in multiple myeloma. Mol Pharm 2018;15:5387-96. DOI PubMed

68. Díaz T, Rodríguez V, Lozano E, et al. The BET bromodomain inhibitor CPI203 improves lenalidomide and dexamethasone activity in in vitro and in vivo models of multiple myeloma by blockade of Ikaros and MYC signaling. Haematologica 2017;102:1776-84. DOI PubMed PMC

69. Lim SL, Xu L, Han BC, Shyamsunder P, Chng WJ, Koeffler HP. Multiple myeloma: Combination therapy of BET proteolysis targeting chimeric molecule with CDK9 inhibitor. PLoS One 2020;15:e232068. DOI PubMed PMC

70. Stubbs MC, Burn TC, Sparks R, et al. The novel bromodomain and extraterminal domain inhibitor INCB054329 induces vulnerabilities in myeloma cells that inform rational combination strategies. Clin Cancer Res 2019;25:300-11. DOI PubMed

71. Falchook G, Rosen S, LoRusso P, et al. Development of 2 bromodomain and extraterminal inhibitors with distinct pharmacokinetic and pharmacodynamic profiles for the treatment of advanced malignancies. Clin Cancer Res 2020;26:1247-57. DOI PubMed PMC

72. Shapiro GI, LoRusso P, Dowlati A, et al. A Phase 1 study of RO6870810, a novel bromodomain and extra-terminal protein inhibitor, in patients with NUT carcinoma, other solid tumours, or diffuse large B-cell lymphoma. Br J Cancer 2021;124:744-53. DOI PubMed PMC

73. Ishiguro K, Kitajima H, Niinuma T, et al. DOT1L inhibition blocks multiple myeloma cell proliferation by suppressing IRF4-MYC signaling. Haematologica 2019;104:155-65. DOI PubMed PMC

74. Yap TA, Winter JN, Giulino-Roth L, et al. Phase I study of the novel enhancer of zeste homolog 2 (EZH2) inhibitor GSK2816126 in patients with advanced hematologic and solid tumors. Clin Cancer Res 2019;25:7331-9. DOI PubMed PMC

75. Dafflon C, Gaulis S, Barys L, et al. DOT1L inhibition is lethal for multiple myeloma due to perturbation of the endoplasmic reticulum stress pathway. Oncotarget 2020;11:956-68. DOI PubMed PMC

76. Tang S, Ma D, Cheng B, et al. Crucial role of HO-1/IRF4-dependent apoptosis induced by panobinostat and lenalidomide in multiple myeloma. Exp Cell Res 2018;363:196-207. DOI PubMed

77. Laubach JP, Tuchman SA, Rosenblatt JM, et al. Phase 1 open-label study of panobinostat, lenalidomide, bortezomib + dexamethasone in relapsed and relapsed/refractory multiple myeloma. Blood Cancer J 2021;11:20. DOI PubMed PMC

78. Mondala PK, Vora AA, Zhou T, et al. Selective antisense oligonucleotide inhibition of human IRF4 prevents malignant myeloma regeneration via cell cycle disruption. Cell Stem Cell 2021;28:623-36.e9. DOI PubMed PMC

79. Das DS, Ray A, Das A, et al. A novel hypoxia-selective epigenetic agent RRx-001 triggers apoptosis and overcomes drug resistance in multiple myeloma cells. Leukemia 2016;30:2187-97. DOI PubMed PMC

80. Cabrales P, Carter C, Oronsky B, Reid T. Rrx-001 is a phase 3 small molecule dual inhibitor of CD47 and Sirp $\alpha$ with activity in multiple myeloma. Blood 2018;132:5623. DOI

81. Zhang Y, Zhou L, Bandyopadhyay D, et al. The covalent CDK7 inhibitor THZ1 potently induces apoptosis in multiple myeloma cells in vitro and in vivo. Clin Cancer Res 2019;25:6195-205. DOI PubMed PMC

82. Czudor Z, Balogh M, Bánhegyi P, et al. Novel compounds with potent CDK9 inhibitory activity for the treatment of myeloma. Bioorg Med Chem Lett 2018;28:769-73. DOI PubMed

83. Hu S, Marineau JJ, Rajagopal N, et al. Discovery and characterization of SY-1365, a selective, covalent inhibitor of CDK7. Cancer Res 2019;79:3479-91. DOI PubMed

84. Cidado J, Boiko S, Proia T, et al. AZD4573 is a highly selective CDK9 inhibitor that suppresses MCL-1 and induces apoptosis in hematologic cancer cells. Clin Cancer Res 2020;26:922-34. DOI PubMed

85. Sun K, Atoyan R, Borek MA, et al. Dual HDAC and PI3K inhibitor CUDC-907 downregulates MYC and suppresses growth of MYC-dependent cancers. Mol Cancer Ther 2017;16:285-99. DOI PubMed

86. Paíno T, Garcia-Gomez A, González-Méndez L, et al. The novel pan-PIM kinase inhibitor, PIM447, displays dual antimyeloma and bone-protective effects, and potently synergizes with current standards of care. Clin Cancer Res 2017;23:225-38. DOI PubMed

87. Paíno T, González-Méndez L, San-Segundo L, et al. Protein translation inhibition is involved in the activity of the pan-PIM kinase inhibitor PIM447 in combination with pomalidomide-dexamethasone in multiple myeloma. Cancers (Basel) 2020;12:2743. DOI PubMed PMC

88. Raab MS, Thomas SK, Ocio EM, et al. The first-in-human study of the pan-PIM kinase inhibitor PIM447 in patients with relapsed and/or refractory multiple myeloma. Leukemia 2019;33:2924-33. DOI PubMed

89. Buettner R, Morales C, Caserta E, et al. Leflunomide regulates c-Myc expression in myeloma cells through PIM targeting. Blood Adv 2019;3:1027-32. DOI PubMed PMC

90. Rosenzweig M, Palmer J, Tsai NC, et al. Repurposing leflunomide for relapsed/refractory multiple myeloma: a phase 1 study. Leuk Lymphoma 2020;61:1669-77. DOI PubMed PMC

91. Vogl DT, Dingli D, Cornell RF, et al. Selective inhibition of nuclear export with oral selinexor for treatment of relapsed or refractory multiple myeloma. J Clin Oncol 2018;36:859-66. DOI PubMed PMC

92. Chari A, Vogl DT, Gavriatopoulou M, et al. Oral Selinexor-dexamethasone for triple-class refractory multiple myeloma. $N$ Engl $J$ 
Med 2019;381:727-38. DOI PubMed

93. Mateos MV, Gavriatopoulou M, Facon T, et al. Effect of prior treatments on selinexor, bortezomib, and dexamethasone in previously treated multiple myeloma. J Hematol Oncol 2021;14:59. DOI PubMed PMC

94. Richard S, Chari A, Delimpasi S, et al. Selinexor, bortezomib, and dexamethasone versus bortezomib and dexamethasone in previously treated multiple myeloma: Outcomes by cytogenetic risk. Am J Hematol 2021;96:1120-30. DOI PubMed

95. Auner HW, Gavriatopoulou M, Delimpasi S, et al. Effect of age and frailty on the efficacy and tolerability of once-weekly selinexor, bortezomib, and dexamethasone in previously treated multiple myeloma. Am J Hematol 2021;96:708-18. DOI PubMed

96. Grosicki S, Simonova M, Spicka I, et al. Once-per-week selinexor, bortezomib, and dexamethasone versus twice-per-week bortezomib and dexamethasone in patients with multiple myeloma (BOSTON): a randomised, open-label, phase 3 trial. Lancet 2020;396:1563-73. DOI PubMed

97. Itoua Maïga R, Cencic R, Chu J, et al. Oxo-aglaiastatin-mediated inhibition of translation initiation. Sci Rep 2019;9:1265. DOI PubMed PMC

98. Grieve $\mathrm{S}$, Wajnberg G, Lees M, et al. TAZ functions as a tumor suppressor in multiple myeloma by downregulating MYC. Blood Adv 2019;3:3613-25. DOI PubMed PMC

99. Ronca R, Ghedini GC, Maccarinelli F, et al. FGF trapping inhibits multiple myeloma growth through c-Myc degradation-induced mitochondrial oxidative stress. Cancer Res 2020;80:2340-54. DOI PubMed

100. Chae YK, Hong F, Vaklavas C, et al. Phase II Study of AZD4547 in patients with tumors harboring aberrations in the FGFR pathway: results from the NCI-MATCH trial (EAY131) subprotocol W. J Clin Oncol 2020;38:2407-17. DOI PubMed PMC

101. Yao R, Xie Y, Sun X, et al. Identification of a novel c-Myc inhibitor 7594-0037 by structure-based virtual screening and investigation of its anti-cancer effect on multiple myeloma. Drug Des Devel Ther 2020;14:3983-93. DOI PubMed PMC

102. Cao Y, Shan H, Liu M, et al. Directly targeting c-Myc contributes to the anti-multiple myeloma effect of anlotinib. Cell Death Dis 2021;12:396. DOI PubMed PMC

103. Shen G, Zheng F, Ren D, et al. Anlotinib: a novel multi-targeting tyrosine kinase inhibitor in clinical development. J Hematol Oncol 2018;11:120. DOI PubMed PMC

104. Simmons JK, Michalowski AM, Gamache BJ, et al. Cooperative targets of combined mTOR/HDAC inhibition promote MYC degradation. Mol Cancer Ther 2017;16:2008-21. DOI PubMed PMC

105. Delmore JE, Issa GC, Lemieux ME, et al. BET bromodomain inhibition as a therapeutic strategy to target c-Myc. Cell 2011;146:90417. DOI PubMed PMC

106. Shi J, Song S, Han H, et al. Potent activity of the bromodomain inhibitor OTX015 in multiple myeloma. Mol Pharm 2018;15:413947. DOI PubMed

107. Lin X, Huang X, Uziel T, et al. HEXIM1 as a robust pharmacodynamic marker for monitoring target engagement of BET family bromodomain inhibitors in tumors and surrogate tissues. Mol Cancer Ther 2017;16:388-96. DOI PubMed

108. Cochran AG, Conery AR, Sims RJ 3rd. Bromodomains: a new target class for drug development. Nat Rev Drug Discov 2019;18:60928. DOI PubMed

109. Stathis A, Bertoni F. BET proteins as targets for anticancer treatment. Cancer Discov 2018;8:24-36. DOI PubMed

110. Alqahtani A, Choucair K, Ashraf M, et al. Bromodomain and extra-terminal motif inhibitors: a review of preclinical and clinical advances in cancer therapy. Future SCi OA 2019;5:FSO372. DOI PubMed PMC

111. Genta S, Pirosa MC, Stathis A. BET and EZH2 inhibitors: novel approaches for targeting cancer. Curr Oncol Rep 2019;21:13. DOI PubMed

112. Sun Y, Han J, Wang Z, Li X, Sun Y, Hu Z. Safety and efficacy of bromodomain and extra-terminal inhibitors for the treatment of hematological malignancies and solid tumors: a systematic study of clinical trials. Front Pharmacol 2020;11:621093. DOI PubMed PMC

113. Cheng Y, He C, Wang M, et al. Targeting epigenetic regulators for cancer therapy: mechanisms and advances in clinical trials. Signal Transduct Target Ther 2019;4:62. DOI PubMed PMC

114. Tu WB, Shiah YJ, Lourenco C, et al. MYC Interacts with the G9a histone methyltransferase to drive transcriptional repression and tumorigenesis. Cancer Cell 2018;34:579-95.e8. DOI PubMed

115. Tremblay-LeMay R, Rastgoo N, Pourabdollah M, Chang H. EZH2 as a therapeutic target for multiple myeloma and other haematological malignancies. Biomark Res 2018;6:34. DOI PubMed PMC

116. Vatapalli R, Sagar V, Rodriguez Y, et al. Histone methyltransferase DOT1L coordinates AR and MYC stability in prostate cancer. Nat Commun 2020;11:4153. DOI PubMed PMC

117. Ishiguro K, Kitajima H, Niinuma T, et al. Dual EZH2 and G9a inhibition suppresses multiple myeloma cell proliferation by regulating the interferon signal and IRF4-MYC axis. Cell Death Discov 2021;7:7. DOI PubMed PMC

118. Oronsky B, Reid TR, Oronsky A, Caroen S, Carter CA, Cabrales P. Brief report: RRx-001 is a c-Myc inhibitor that targets cancer stem cells. Oncotarget 2018;9:23439-42. DOI PubMed PMC

119. Caroen S, Oronsky B, Carter C, Lybeck M, Oronsky A, Reid T. Rationale and necessity for delivery of RRx-001, a Myc and CD47 antagonist, by intravenous blood mix. Expert Opin Drug Deliv 2020;17:741-2. DOI PubMed

120. Oronsky B, Carter CA, Caroen S, Scribner C, Oronsky A, Reid TR. RRx-001, a first-in-class small molecule inhibitor of MYC and a downregulator of CD47, is an "erythrophagoimmunotherapeutic". Oncoimmunology 2020;9:1746172. DOI PubMed PMC

121. Stein EM, Garcia-Manero G, Rizzieri DA, et al. The DOT1L inhibitor pinometostat reduces H3K79 methylation and has modest clinical activity in adult acute leukemia. Blood 2018;131:2661-9. DOI PubMed PMC

122. Kelso TW, Baumgart K, Eickhoff J, et al. Cyclin-dependent kinase 7 controls mRNA synthesis by affecting stability of preinitiation 
complexes, leading to altered gene expression, cell cycle progression, and survival of tumor cells. Mol Cell Biol 2014;34:3675-88. DOI PubMed PMC

123. Chipumuro E, Marco E, Christensen CL, et al. CDK7 inhibition suppresses super-enhancer-linked oncogenic transcription in MYCNdriven cancer. Cell 2014;159:1126-39. DOI PubMed PMC

124. Kwiatkowski N, Zhang T, Rahl PB, et al. Targeting transcription regulation in cancer with a covalent CDK7 inhibitor. Nature 2014;511:616-20. DOI PubMed PMC

125. Chesler L, Schlieve C, Goldenberg DD, et al. Inhibition of phosphatidylinositol 3-kinase destabilizes Mycn protein and blocks malignant progression in neuroblastoma. Cancer Res 2006;66:8139-46. DOI PubMed PMC

126. Roohi A, Hojjat-Farsangi M. Recent advances in targeting mTOR signaling pathway using small molecule inhibitors. J Drug Target 2017;25:189-201. DOI PubMed

127. Pei Y, Liu KW, Wang J, et al. HDAC and PI3K antagonists cooperate to inhibit growth of MYC-driven medulloblastoma. Cancer Cell 2016;29:311-23. DOI PubMed PMC

128. Chiu H, Buono R, Jackson LV, et al. Reduced eIF4E function impairs B-cell leukemia without altering normal B-lymphocyte function. iScience 2021;24:102748. DOI PubMed PMC

129. Mougiakakos D, Bach C, Böttcher M, et al. The IKZF1-IRF4/IRF5 axis controls polarization of myeloma-associated macrophages. Cancer Immunol Res 2021;9:265-78. DOI PubMed

130. Pal I, Safari M, Jovanovic M, Bates SE, Deng C. Targeting translation of mRNA as a therapeutic strategy in cancer. Curr Hematol Malig Rep 2019;14:219-27. DOI PubMed

131. Taroncher-Oldenburg G, Müller C, Obermann W, Ziebuhr J, Hartmann RK, Grünweller A. Targeting the DEAD-Box RNA helicase eIF4A with Rocaglates-A pan-antiviral strategy for minimizing the impact of future RNA virus pandemics. Microorganisms 2021;9:540. DOI PubMed PMC

132. Sun XX, He X, Yin L, Komada M, Sears RC, Dai MS. The nucleolar ubiquitin-specific protease USP36 deubiquitinates and stabilizes c-Myc. Proc Natl Acad Sci U S A 2015;112:3734-9. DOI PubMed PMC

133. Huang HL, Weng HY, Wang LQ, et al. Triggering Fbw7-mediated proteasomal degradation of c-Myc by oridonin induces cell growth inhibition and apoptosis. Mol Cancer Ther 2012;11:1155-65. DOI PubMed

134. Yang D, Hurley LH. Structure of the biologically relevant G-quadruplex in the c-MYC promoter. Nucleosides Nucleotides Nucleic Acids 2006;25:951-68. DOI PubMed

135. Brooks TA, Hurley LH. Targeting MYC Expression through G-Quadruplexes. Genes Cancer 2010;1:641-9. DOI PubMed PMC

136. Brown RV, Danford FL, Gokhale V, Hurley LH, Brooks TA. Demonstration that drug-targeted down-regulation of MYC in nonHodgkins lymphoma is directly mediated through the promoter G-quadruplex. J Biol Chem 2011;286:41018-27. DOI PubMed PMC

137. Ferreira R, Schneekloth JS Jr, Panov KI, Hannan KM, Hannan RD. Targeting the RNA polymerase I transcription for cancer therapy comes of age. Cells 2020;9:266. DOI PubMed PMC

138. Khot A, Brajanovski N, Cameron DP, et al. First-in-human RNA polymerase I transcription inhibitor CX-5461 in patients with advanced hematologic cancers: results of a phase I dose-escalation study. Cancer Discov 2019;9:1036-49. DOI PubMed

139. Leung AWY, Anantha M, Dragowska WH, Wehbe M, Bally MB. Copper-CX-5461: A novel liposomal formulation for a small molecule rRNA synthesis inhibitor. J Control Release 2018;286:1-9. DOI PubMed

140. Calabrese DR, Chen X, Leon EC, et al. Chemical and structural studies provide a mechanistic basis for recognition of the MYC Gquadruplex. Nat Commun 2018;9:4229. DOI PubMed PMC

141. Gaikwad SM, Phyo Z, Arteaga AQ, et al. A small molecule stabilizer of the MYC G4-quadruplex induces endoplasmic reticulum stress, senescence and pyroptosis in multiple myeloma. Cancers (Basel) 2020;12:2952. DOI PubMed PMC

142. Minard A, Morgan D, Raguseo F, et al. A short peptide that preferentially binds c-MYC G-quadruplex DNA. Chem Commun (Camb) 2020;56:8940-3. DOI PubMed

143. Webb MS, Tortora N, Cremese M, et al. Toxicity and toxicokinetics of a phosphorothioate oligonucleotide against the c-myc oncogene in cynomolgus monkeys. Antisense Nucleic Acid Drug Dev 2001;11:155-63. DOI PubMed

144. Arora V, Knapp DC, Smith BL, et al. c-Myc antisense limits rat liver regeneration and indicates role for c-Myc in regulating cytochrome P-450 3A activity. J Pharmacol Exp Ther 2000;292:921-8. PubMed

145. Wang H, Mannava S, Grachtchouk V, et al. c-Myc depletion inhibits proliferation of human tumor cells at various stages of the cell cycle. Oncogene 2008;27:1905-15. DOI PubMed PMC

146. Tolcher AW, Papadopoulos KP, Patnaik A, et al. Safety and activity of DCR-MYC, a first-in-class Dicer-substrate small interfering RNA (DsiRNA) targeting MYC, in a phase I study in patients with advanced solid tumors. JCO 2015;33:11006. DOI

147. Morelli E, Biamonte L, Federico C, et al. Therapeutic vulnerability of multiple myeloma to MIR17PTi, a first-in-class inhibitor of pri-miR-17-92. Blood 2018;132:1050-63. DOI PubMed PMC

148. Caracciolo D, Scionti F, Juli G, et al. Exploiting MYC-induced PARPness to target genomic instability in multiple myeloma. Haematologica 2021;106:185-95. DOI PubMed PMC

149. Sorolla A, Wang E, Golden E, et al. Precision medicine by designer interference peptides: applications in oncology and molecular therapeutics. Oncogene 2020;39:1167-84. DOI PubMed PMC

150. Berg T, Cohen SB, Desharnais J, et al. Small-molecule antagonists of Myc/Max dimerization inhibit Myc-induced transformation of chicken embryo fibroblasts. Proc Natl Acad Sci U S A 2002;99:3830-5. DOI PubMed PMC

151. Yin X, Giap C, Lazo JS, Prochownik EV. Low molecular weight inhibitors of Myc-Max interaction and function. Oncogene 2003;22:6151-9. DOI PubMed 
152. Fletcher S, Prochownik EV. Small-molecule inhibitors of the Myc oncoprotein. Biochim Biophys Acta 2015;1849:525-43. DOI PubMed PMC

153. Kiessling A, Wiesinger R, Sperl B, Berg T. Selective inhibition of c-Myc/Max dimerization by a pyrazolo[1,5-a]pyrimidine. ChemMedChem 2007;2:627-30. DOI PubMed

154. Hart JR, Garner AL, Yu J, et al. Inhibitor of MYC identified in a Kröhnke pyridine library. Proc Natl Acad Sci U S A 2014;111:12556-61. DOI PubMed PMC

155. Mo H, Henriksson M. Identification of small molecules that induce apoptosis in a Myc-dependent manner and inhibit Myc-driven transformation. Proc Natl Acad Sci U S A 2006;103:6344-9. DOI PubMed PMC

156. Jeong KC, Kim KT, Seo HH, et al. Intravesical instillation of c-MYC inhibitor KSI-3716 suppresses orthotopic bladder tumor growth. J Urol 2014;191:510-8. DOI PubMed

157. Giorello L, Clerico L, Pescarolo MP, et al. Inhibition of cancer cell growth and c-Myc transcriptional activity by a c-Myc helix 1-type peptide fused to an internalization sequence. Cancer Res 1998;58:3654-9. PubMed

158. Beaulieu ME, Jauset T, Massó-Vallés D, et al. Intrinsic cell-penetrating activity propels Omomyc from proof of concept to viable anti-MYC therapy. Sci Transl Med 2019;11:eaar5012. DOI PubMed PMC

159. Boise LH. A miRaculous new therapy in myeloma? Blood 2018;132:983-5. DOI PubMed 